\title{
Development of a First-Principles Hybrid Boiler Model for Oxy-Combustion Power Generation System
}

\author{
Jinliang Ma ${ }^{1,2}$, John P. Eason ${ }^{3}$, Alexander W. Dowling ${ }^{3}$, Lorenz T. Biegler ${ }^{3}$, and David C. \\ Miller $^{1}$ \\ ${ }^{1}$ National Energy Technology Laboratory, Pittsburgh, PA 15236, USA \\ ${ }^{2}$ AECOM, Morgantown, WV 26505, USA \\ ${ }^{3}$ Carnegie Mellon University, Department of Chemical Engineering, Pittsburgh, PA 15289, USA
}

\begin{abstract}
The design of an oxy-combustion system for $\mathrm{CO}_{2}$ capture involves the integration of multiple devices including air separation unit, coal-fired boiler, steam turbine, flue gas cleanup, recycle, and compression units. Thousands of design parameters for the entire system need to be optimized to achieve the lowest cost per kilowatt-hour of electricity generated. An appropriate first-principles based boiler model with short computer execution time but yet reasonable accuracy in both air-fired and oxy-fired configurations is highly desired. To this end, a hybrid boiler model with 1-D resolution for main flow and reaction related calculations and 3-D resolution for radiative heat transfer was developed as a part of the oxy-combustion subtask of the Carbon Capture and Simulation Initiative (CCSI) sponsored by U.S. Department of Energy. The developed model is able to automatically generate a 3-D mesh based on user-specified furnace shape for the calculation of radiative heat transfer using discrete ordinates method. The 3-D cells are assigned to individual regions along the furnace height, forming 1-D zones in which conservations of mass and energy in both gas and particle phases are enforced. The kinetics of heterogeneous reactions between char particles and gas reactants are modeled zone by zone in Lagrangian framework. Gas phase chemistry in each zone is simplified based on chemical equilibrium. The submodels for calculating the radiative properties of the gas and particle phases and those for calculating the heterogeneous char reactions are suitable for both air-fired and oxy-fired conditions. A typical boiler model can be converged in approximately one minute on a personal computer and, therefore, is suitable for the generation of reduced order models in algebraic form which could be used for the large-scale multivariable optimization of the oxy-combustion systems. By modeling a utility boiler in both air-fired and oxy-fired configurations and comparing the results to those from computational fluid dynamics simulations, the hybrid boiler model was found to give very comparable predictions in major boiler performance parameters such as furnace exit gas temperature, heat losses to walls, and unburned carbon in fly ash. By modeling a small test furnace, it was found that with the adjustments on a "mixedness" related effectiveness factor for the char combustion and gasification reactions, the boiler model is able to correctly predict the trends of incident radiation heat flux profile along the furnace axial length as well as the trend of the unburned carbon in both air-fired and oxy-fired configurations.
\end{abstract}


Keywords: Boiler model, Oxy-combustion, Pulverized coal combustion, System optimization, Carbon capture, Discrete ordinates method

\section{Introduction}

Pulverized coal-fired (PC) boilers currently dominate the electric power generation industry. However, as with any fossil fuel based system, conventional air-fired PC boilers generate a large amount of $\mathrm{CO}_{2}$, a greenhouse gas, which exits the boilers along with a large amount of $\mathrm{N}_{2}$ from air. Oxy-combustion is a modern combustion technology in which $\mathrm{O}_{2}$ is first separated from $\mathrm{N}_{2}$ in air and then mixed with the recycled flue gas to burn pulverized coal, producing a flue gas that contains mainly $\mathrm{H}_{2} \mathrm{O}$ and $\mathrm{CO}_{2}$ and is, therefore, easier to purify for capture, utilization, and storage of $\mathrm{CO}_{2}$. Several studies have estimated the performance penalty of $\mathrm{CO}_{2}$ capture in an oxy-fired coal power plant to be 8 to 10 thermal efficiency percentage points (Burhe, 2005; Fu, 2010). The potential for penalty reduction includes refinement of air separation and $\mathrm{CO}_{2}$ compression (Tranier, 2011), as well as integration of waste heat from air and $\mathrm{CO}_{2}$ compressors into the steam cycle ( $\mathrm{Fu}, 2015$; Soundararajan, 2014), and hot flue gas recycle (Hagi, 2014).

These simulation-based oxy-combustion studies typically rely on simplified furnace models, such as a Gibbs free energy minimization model, to predict outlet flue gas stream in chemical equilibrium. Optimization with such models, however, is misguided, as the results suggest no excess $\mathrm{O}_{2}$ should be fed into the furnace to maximize overall process thermal efficiency (Dowling, 2013). Thus in practice, the modeler must specify a (somewhat arbitrary) lower bound for the $\mathrm{O}_{2}$ mole fraction in the flue gas without considering its effect on coal burnout. Also, these equilibrium reactor models cannot be used to optimize furnace geometry, predict the heat transfer profiles, or predict the result of primary vs. secondary recycle strategies and other important design decisions. Furthermore, combustion in a $\mathrm{CO}_{2} / \mathrm{O}_{2}$ atmosphere is drastically different than a $\mathrm{N}_{2} / \mathrm{O}_{2}$ atmosphere, and design correlations for air-fired boilers do not apply for oxy-combustion. Although the detailed physics inside the furnace can be modeled using 3-D Computational Fluid Dynamics (CFD) software, the CFD model is very CPU intensive and, therefore, inappropriate for generating reduced models for system-wide optimization. Thus, for detailed optimization of an oxy-combustion process, it is highly desired that a first-principles based boiler model be developed that is more sophisticated than the 0-D ideal reactor model but much faster than the 3-D CFD model. After validated, the boiler model could also be used by boiler manufacturers as a software tool to design the overall dimensions of boilers and their internal heat transfer surfaces.

A hybrid boiler model with 1-D resolution along the height of a radiant furnace for flow and reaction related calculations and 3-D resolution for radiative heat transfer calculations has been developed as a part of the Carbon Capture and Simulation Initiative (CCSI) sponsored by the U.S. Department of Energy. This paper describes the assumptions, principles, and corresponding equations inside the hybrid boiler model as well as the numerical procedures to 
achieve a converged solution. The application of the model to a large-scale utility boiler and a small test furnace is also described. The results from the modeling of the utility boiler in both air-fired and oxy-fired configurations are presented and compared to the results of the corresponding CFD models found in the literature. The results from modeling the test furnace are also presented and compared to reported experimental results in both air-fired and oxy-fired configurations.

\section{Development of Hybrid Boiler Model}

A PC boiler with a specified heating rate is typically designed to ensure a) the complete combustion of fuel with a minimal amount of oxidant and highest possible boiler efficiency, b) the minimal amount of pollutants is formed and c) the required amount of heat is transferred to the water walls and superheater walls, such that the Furnace Exit Gas Temperature (FEGT) is kept below the fusion temperature of the coal ash, avoiding the fouling on the downstream convective heat transfer surfaces. Historically the design of radiant furnaces by boiler manufacturers was carried out using company proprietary empirical correlations such as those approximate curves published by Babcock \& Wilcox (1992). Those empirical curves are usually plotted or expressed in some forms of non-dimensional parameters based on the principle of similarities, and are valid for conventional firing configurations. However, when the firing configuration is dramatically changed as in the case of oxy-combustion, those empirical correlations are most likely invalid. Therefore, models based on first principles have to be developed such that design parameters for the combustion system can be optimized.

Zero-dimensional ideal reactor models, such as models built into commercial process simulation software, typically include mass and energy balances and calculate equilibrium by minimizing Gibbs free energy of the outlet stream. When these models are used for PC boilers, however, the carbon burnout and heat absorption by the water wall and superheaters are usually specified as model inputs rather than predicted by the models themselves. Thus zerodimensional models are unsuitable for designing the boiler geometry, burner locations, and other parameters and for accurately calculating the cost of the boiler and the cost of electricity. On the other hand, comprehensive 3-D CFD models can simulate the detailed flow dynamics, heat transfer, and chemistry in the boiler but are too time-consuming, with computational times from several hours to weeks to evaluate a single operating point. Zone-based models simplified from the CFD models in both spatial resolution and in physics provide a good compromise between model accuracy and required CPU time. When developed with reasonable assumptions and good solution strategies, zone-based models are the best candidate for practical furnace design and optimization. Some zone-based boiler models found in the literature (e.g., Lowe et al., 1975; Lawson and Ziesler, 1996) are based on the zonal method for radiation heat transfer calculation developed by Hottel and Sarofim (1967). In those models, the flow domain of a radiant furnace was divided into multiple zones, either in 1-D (along the height) or 2-D (usually cylindrical) with water walls and internal superheater walls as heat transfer surfaces that enclose the flow domain. 
Each zone was assumed to be isothermal with predefined coal burnouts and predefined fuel and oxidant flow pattern. In Hottel's zonal method, directed-flux areas between pairs of two heat exchange elements (wall surface or volume zone) need to be calculated. When the geometry of the radiant furnace is complicated and radiation properties of the participating media vary from zone to zone, an analytical expression of the directed-flux area (a multidimensional integral) is rarely possible. Either simplifications in geometry and radiation properties have to be made or complicated, CPU-intensive, statistical simulation methods such as Monte Carlo methods have to be used (e.g. Lawson and Ziesler, 1996) to calculate the directed-flux area. A more dramatically simplified zone-based method, known as Russian normative method was developed by Kouznetsov et al. (1973). It was widely used in Russia and was later adopted by the boiler manufacturers in China in the 1970s (Beijing Boiler Works, 1973). In the Russian normative model, the radiation properties of the gas, particles, and boundary walls as well as the radiative heat exchange between two neighboring zones are calculated based on semi-empirical correlations that account for the fuel type, water wall type, and other design parameters. The Russian normative method has also been adopted recently as part of the ash slagging and fouling prediction model for coal and biomass co-firing (Plaza, 2013). Since some model parameters are simply empirical correlations, the Russian normative zone method is not considered as a strictly first-principles model and may not be valid for oxy-combustion configurations. Moreover, most zone-based models found in the literature do not couple reaction kinetics with heat transfer. Usually the coal burnout in each zone has to be predefined, which again limits the model's ability to predict boiler performance in non-conventional firing configurations.

Models for simulating radiative heat transfer with participating media of gas and particles have been dramatically improved since the 1980s. Advanced models such as the discrete ordinates (DO) method have been applied to commercial CFD software packages and implemented on discretized 3-D meshes (Fiveland, 1988; Murthy and Mathur, 1998). The DO method can solve radiation intensity in space and in predefined directions known as discrete ordinates. It considers all terms in the radiative transfer equation including emission, scattering, and adsorption of participating media in both gas and solid phases. The main challenge for zonebased methods reviewed above is the radiation heat transfer in 3-D and $4 \pi$ solid angle. Modern methods for solving radiative transfer equations such as the DO method provide an effective first-principles-based approach to tackle the problem with reasonable accuracy and short enough CPU time if the mesh size is not too large; this avoids the complicated algorithms to calculate the directed-flux areas in Hottel's zonal method. Since the DO method is usually performed on a 3$\mathrm{D}$ mesh, it is desired that the zones be refined to form a computational mesh, similar to that of a CFD model but with much coarser resolution (e.g., with the number of cells reduced to $5 \%$ of the CFD model), for the radiation heat transfer calculation. Therefore, a hybrid approach with a 3-D mesh for radiation calculations and 1-D zones for kinetics and mass/energy balance calculations was developed in this work. Compared with the comprehensive CFD modeling approach, the hybrid approach does not solve the momentum and turbulence partial differential equations; however, the continuity and enthalpy equations are solved based on the 1-D zones. Since the 
number of discretized elements is dramatically reduced, the number of unknown variables is also reduced, and CPU time is a few orders of magnitude less. Moreover, since the radiative transfer equation is strictly solved on a 3-D mesh without any simplifications, an accurate prediction regarding the radiation heat transfer can be achieved. The effects due to the blockages of the radiation from the fire ball by internal surfaces such as superheater walls and effects due to sloped hopper, sloped nose, and furnace corners can be correctly predicted.

\subsection{Spatial Discretization}

Figure 1 illustrates a typical front wall fired subcritical PC boiler. The flow domain for the boiler model is the volume enclosed by the front, the rear and the two side walls. The bottom part of the front and rear walls forms the hopper, and the upper part of the rear wall forms the nose. The exit of the boiler model is typically set at the vertical plane above the nose tip. There are internal radiative heat transfer surfaces inside the flow domain, such as the platen superheater panels shown in Figure 1. Coal and oxidant are fed to the flow domain through the burners and sometimes overfire ports. The overall flow direction inside the boiler is upward below the nose and then to the rear wall at the model exit. Since the combustion products inside the boiler flow upward, the PC boiler is divided to multiple sections along the height of the furnace, forming 1 D zones separated by horizontal planes. This zonal arrangement can be applied to typical wallfired and tangentially-fired boilers but not to arch-fired boilers. Typically 10 to 20 zones along the furnace height can be predefined by the user. The hopper region is usually the region without inlet or outlet flow. It forms a single "dead" zone with its flue gas composition assumed to be identical to its neighboring burner zone. To calculate the radiative heat transfer using the DO method, the volume in each zone is discretized further to form a 3-D computational mesh similar to that of a CFD model but with much coarser resolution. A single volume unit of the mesh used for radiation calculation is called a cell, and a zone consists of multiple cells. Each zone is modeled as a well-mixed ideal reactor with uniform temperature and uniform flow properties except for the radiative intensity, which varies from cell to cell in each zone. The continuity equation becomes the mass balance equation imposed for each zone. While the reacting flow inside the furnace is solved in 1-D along the height of the furnace, the radiative heat transfer is solved in 3-D. The 3-D mesh is generated automatically based on user specified furnace geometry and discretization inputs in terms of cell numbers in furnace's height, width and depth

directions. This 1-D and 3-D hybrid approach has not been reported in the literature and is a unique feature of the boiler model. 


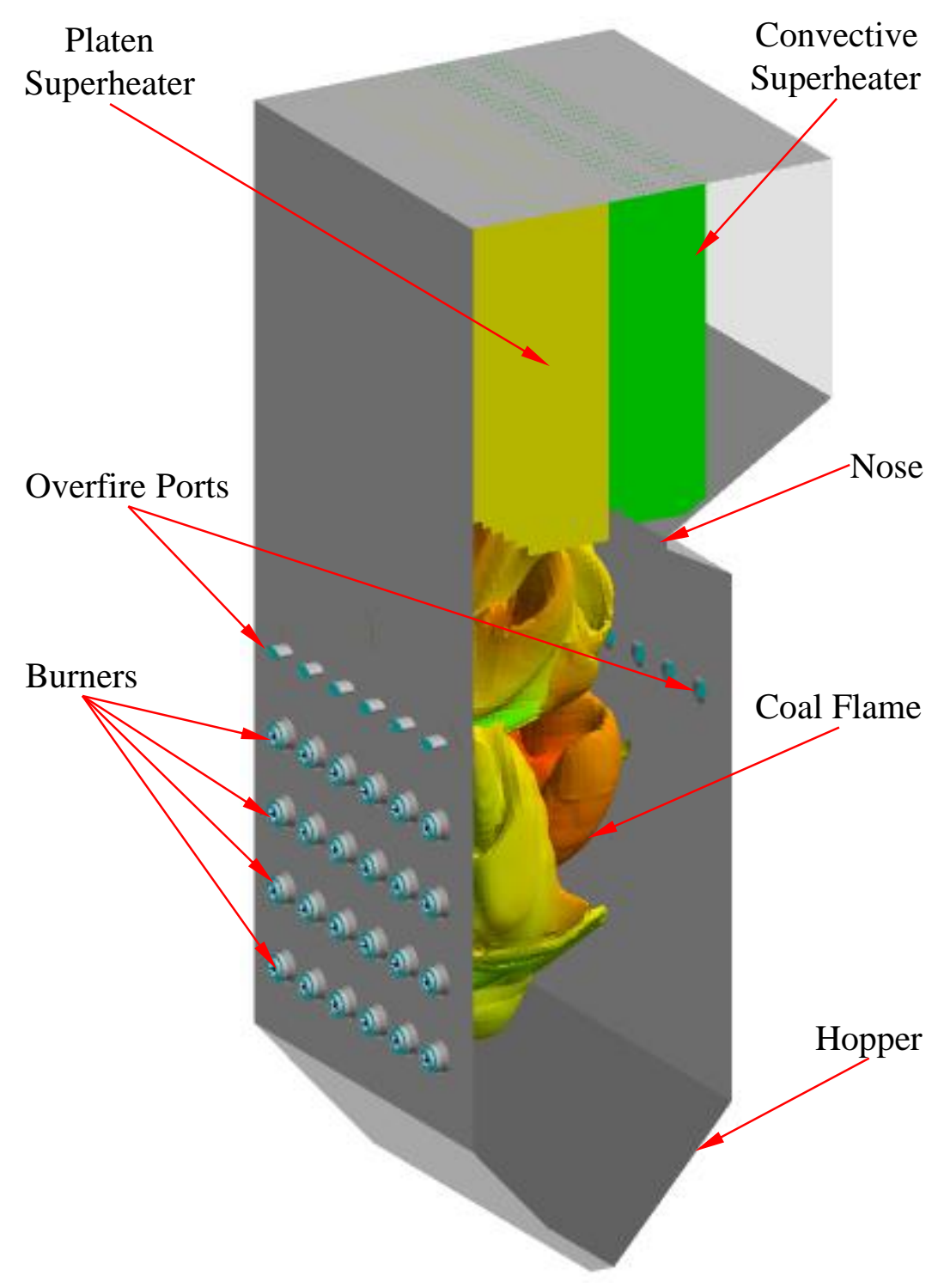

Figure 1. Illustration of a typical PC boiler

Figure 2 shows the 1-D zones and the 3-D mesh of the boiler model for a typical pulverized coal-fired utility boiler consisting of a hopper at the bottom and a nose near the flue gas exit. Note again that the flue gas exit plane here is defined as the vertical plane above the nose tip, corresponding to the plane where the Furnace Exit Gas Temperature (FEGT) is defined. The radiant platen superheater panels, as shown on the left of Figure 2 in green, are also included in the model as boundary walls (modeled as faces of no thickness) while the convective superheaters, usually downstream of the vertical exit plane, are excluded from the radiant furnace model. The platen superheater and wing division walls, if any, are assumed to be parallel to the two side walls and evenly spaced along the furnace width. Care needs to be taken when specifying the number of the cells along the furnace width such that there are at least two cells between two neighboring internal wall surfaces. The 3-D mesh consists of unstructured 
hexahedron cells with top and bottom faces always in horizontal planes and the number of cells in each direction constant throughout the 3-D domain. This 3-D mesh arrangement is suitable for typical PC boiler designs since the volume of the radiant furnace can be created by extruding the polygon shape of the left side wall. It allows for automatic mesh generation. Notice that the cells near the hopper slopes and the nose are "body-fitted".
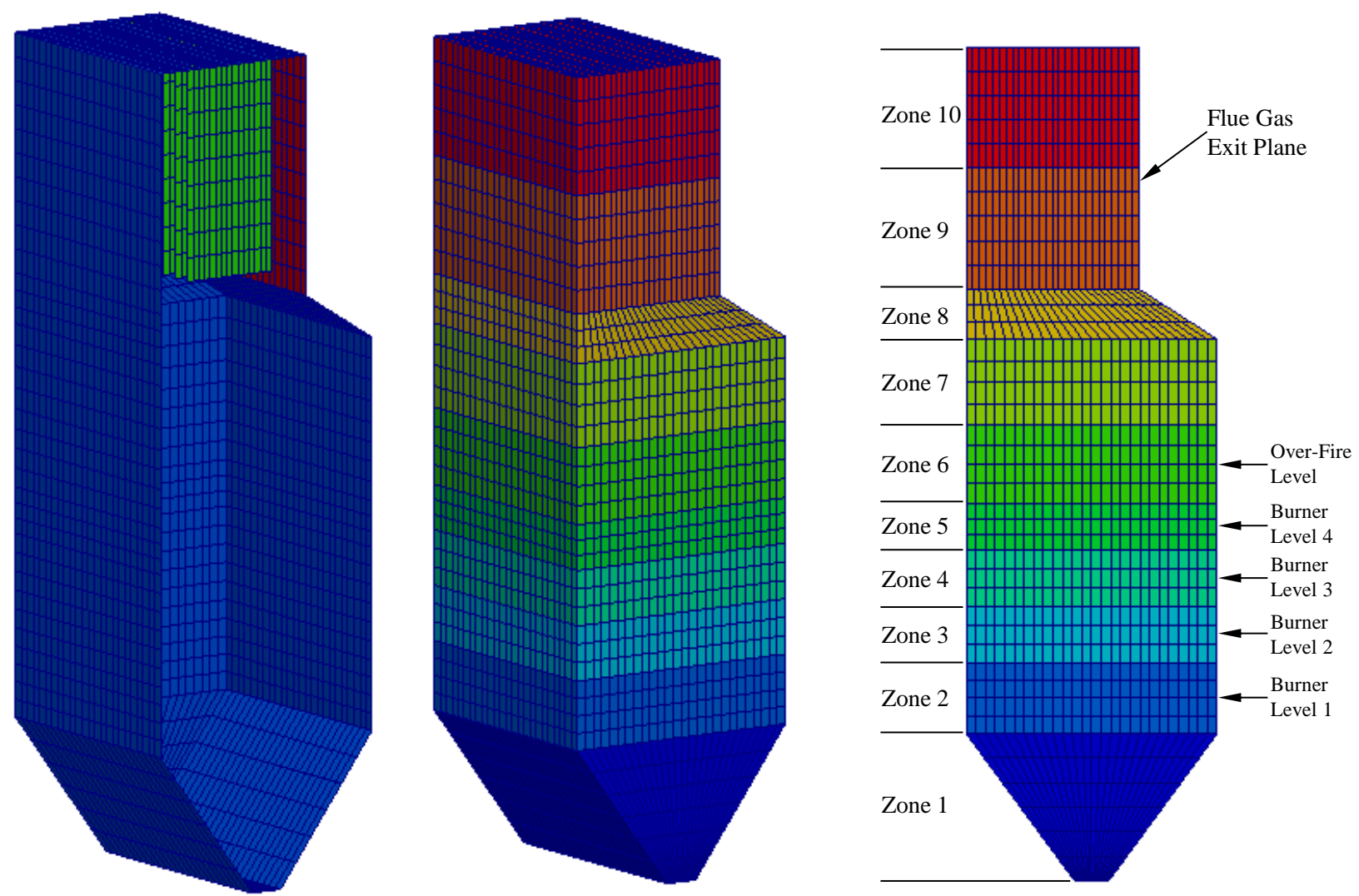

Figure 2. 3-D mesh and 1-D zones in a hybrid boiler model

The 1-D zones are numbered from the hopper to the roof of the furnace with the first zone always covering the entire hopper. The number of zones along the height is a user input. The fuel and oxidant are fed to the furnace at different elevations through burners and overfire stream ports. The elevations and the feed stream data are also user inputs.

\subsection{Model assumptions}

Seven main assumptions are made in the proposed model.

1. Uneven spatial velocity, temperature and other property distributions within each zone are ignored, and uniform properties except for radiation intensity are assigned to all cells in each zone. 
2. Gas phase reactions in each zone are in chemical equilibrium. In other words, the reaction kinetics of the homogeneous reactions in the gas phase are ignored. However, the amount of unreacted mass in the solid phase in each zone is calculated from char oxidation and gasification kinetics. Each zone is modeled as a well-mixed reactor.

3. Velocity differences between coal particles and the gas phase are neglected. Coal particles are assumed to have the same velocities as the gas mixture and hence the same average residence time as the gas mixture.

4. Coal particles have the same temperature as the gas phase in each zone.

5. Moisture evaporation and coal devolatilization are very fast processes and occur immediately after coal particles enter a zone in the radiant furnace. Ash from coal is inert and stays in the particle phase. Coal particles do not fragment.

6. Convective heat transfer between boundary walls and the gas mixtures in a zone is estimated based on a correlation for fully developed flow in a circular pipe of a diameter equal to the hydraulic diameter of the zone.

7. Inner side of furnace walls including the superheater walls are gray and diffuse.

The assumption of uniform properties in each zone (Assumption 1) is the simplification made for the 1-D model. It is well known that pulverized coal burners are designed to generate swirling flows near the burner outlets to stabilize the coal flames and to reduce the generation of $\mathrm{NO}_{\mathrm{x}}$ (Babcock \& Wilcox, 1992). The 1-D resolution is certainly not good enough for modeling the complicated flow field near a coal burner and for assisting burner design. However, the swirling flow can enhance the mixing between fuel and oxidant, making the well-mixed reactor assumption more realistic than the case of straight flow. If multiple zones are used to cover a diffusion flame that is not well mixed in each of the zones, reaction rates calculated based on the uniform reactant concentrations may be over-predicted, especially for the char/gas heterogeneous reactions, and certain effectiveness factors are optionally used to account for the mixing effect. The effects of uniform distribution assumption on overall heat transfer rate along the furnace walls are more complicated. Pulverized coal flame is a diffusion flame with gas temperatures in the flame region much higher than those in the rest of the zone, especially in the region near boiler wall. On one hand, using mean temperature results in the under-prediction of radiative emission of the diffusion flame, which is a function proportional to the $4^{\text {th }}$ power of temperature and part of which travels through the participating gas and particle media and eventually reaches furnace walls. Therefore, this effect results in the under-prediction of radiative heat absorption by the wall. On the other hand, using mean temperature that is higher than the actual near-wall gas temperature results in over-prediction of the radiative emission and, hence, the overprediction of the radiative heat absorption by the wall. It is hoped that the two effects compensate each other such that the simplification does not cause significant error in radiative heat absorbed by furnace walls. It is also believed that the compensation is more significant for a larger and, hence, optically thicker boiler. 
Assumption 2 is generally valid since the temperatures in the radiant furnace are always very high, which causes gas phase chemical reactions to reach equilibrium. Actually most CFD models, such as the mixture fraction based CFD model (ANSYS Fluent manual, 2015) for turbulent combustion, employ a similar assumption, except that the time-averaged equilibrium properties due to turbulence such as temperature and species mole fractions are not calculated based on the average mixture fractions but rather by convoluting over a probability density function for the mixture fractions such that the effect on gas phase reaction due to turbulent mixing is accounted for. The proposed boiler model does not model the turbulence and the variance of mixture fractions. Therefore, Assumption 2 ignores the turbulent mixing effects and results in over-prediction of mean gas temperatures and under-prediction of unburned $\mathrm{CO}$ in the gas phase. The flue gas stream leaving a boiler typically contain around $100 \mathrm{ppm} \mathrm{CO}$ while the equilibrium $\mathrm{CO}$ is usually around a few ppm or less. This discrepancy in $\mathrm{CO}$ prediction does not cause significant error in the predictions of FEGT and total heat absorption by boiler walls.

Assumption 3 is reasonable since pulverized coal particles are very small ( $<200$ micron) and the slip velocity of a coal particle (the difference of velocities between a particle and the gas in its vicinity) is negligible.

Assumption 4 is also reasonable since the maximum temperature difference between coal particles and the nearby gas mixture is usually less than $50 \mathrm{~K}$ based on some CFD simulations, which is again a consequence of small particle sizes. This assumption also simplifies the Lagrangian particle tracking model discussed in Section 2.3.3. It eliminates the need for particle energy equation, which is usually stiff and requires implicit method to solve since heterogeneous reaction rates are very sensitive to particle temperature. Moreover, the energy balance can be performed easily over the combined stream of gas and particles without treating the two phases separately with exchange of energy source between them. This approach reduces required CPU time but could slightly reduce the model accuracy. The improvement on model accuracy and the penalty on required CPU time if the energy equations of gas and particles are solved separately need to be explored in the future.

The first part of Assumption 5 is valid because the temperatures inside a radiant furnace are very high, coal particles are heated up very quickly upon their entry to the furnace, and the moisture vaporization and coal devolatilization processes are typically completed within 100 milliseconds. Note that a high heating rate usually causes a higher volatile yield and, therefore, a volatile yield higher than that from coal proximate analysis should be used as the boiler model input.

For a large-scale utility boiler (e.g. a $500 \mathrm{MW}$ unit), the ratio of the wall surface area to the volume of the furnace is very small and the convective heat transfer rate is relatively small compared to the radiative heat transfer rate. Based on CFD model simulations, radiative heat transfer accounts for more than $95 \%$ of total heat transfer in the radiant part of a boiler (excluding convective superheaters). Convective heat transfer at wall boundaries of a cell in a 
CFD model is typically calculated by a wall function that correlates the convective heat transfer flux with gas velocity, turbulence parameters, distance from the cell centroid to the wall, and the temperatures of the gas and the wall (e.g. ANSYS Fluent, 2015). Since turbulence is not modeled in the hybrid boiler model, the wall function approach cannot be applied. Empirical correlation for circular tubes, although may not so accurate, is a simple method to estimate the convective heat transfer coefficient at the wall boundary. Note that only radiant platen superheaters are included in the proposed boiler model with exit plane set at the vertical plane above the nose tip. Convective superheaters are usually located downstream of that exit plane and are considered with the remaining plant models using algebraic equations in an optimization modeling environment for an oxycombustion system (Dowling, 2014).

Assumption 7 is usually valid since furnace tube walls are diffuse and their emissivity is usually not wavelength dependent.

\subsection{Governing Equations}

\subsubsection{Convective Heat Transfer}

The convective heat transfer takes place at furnace enclosure wall and superheater walls. The heat transfer coefficient in each zone can be estimated using the average gas velocity calculated based on the average cross sectional area of the zone. The average cross sectional area $\bar{A}_{z o n e, j}$ for Zone $j$ is calculated from the volume of the zone $V_{z o n e, j}$ and the height of the zone as shown in Eqn. 1.

$$
\bar{A}_{z o n e, j}=\frac{V_{z o n e, j}}{Y_{z o n e, j}-Y_{z o n e, j-1}}
$$

where $Y_{z o n e, j}$ is the Y coordinate (in height direction) of the top plane of Zone $j$. The average gas velocity $\bar{u}_{g a s, j}$ for Zone $j$ is calculated from the mass flow rate of the gas leaving the zone $\dot{m}_{g a s, j}$ and its density $\rho_{g a s, j}$ as shown in Eqn. 2.

$$
\bar{u}_{g a s, j}=\frac{\dot{m}_{g a s, j}}{\rho_{g a s, j} \bar{A}_{z o n e, j}}
$$

Empirical correlations for circular tubes are used to calculate the Nusselt number with tube diameter replaced by the average hydraulic diameter of the zone $\bar{D}_{h, j}$, which is calculated from the average cross sectional area $\bar{A}_{z o n e, j}$ and the average wetted perimeter of the cross section $\bar{P}_{\text {zone }, j}$.

$$
\bar{D}_{h, j}=\frac{\bar{A}_{z o n e, j}}{\bar{P}_{\text {zone }, j}}
$$

Reynolds number for Zone $j \operatorname{Re}_{z o n e, j}$ is calculated using the bulk gas properties as shown in Eqn. 4. 


$$
\operatorname{Re}_{z o n e, j}=\frac{\bar{u}_{z o n e, j} \bar{D}_{h, j} \rho_{\text {gas }, j}}{\mu_{\text {gas }, j}}
$$

where $\rho_{g a s, j}$ and $\mu_{g a s, j}$ are density and viscosity of the gas mixture evaluated at bulk gas temperature or zone temperature, respectively. Prandtl number of the gas mixture is also evaluated at zone temperature.

$$
\operatorname{Pr}_{z o n e, j}=\frac{C_{p, j} \mu_{g a s, j}}{k_{g a s, j}}
$$

where $C_{p . g a s, j}$ and $k_{g a s, j}$ are heat capacity and thermal conductivity of the gas mixture in Zone $j$, respectively.

For large-scale utility boilers, Reynolds number is usually greater than $10^{4}$ and the correlation of Sieder and Tate (Bird et al., 1960) for fully developed turbulent flow is used to calculate the Nusselt number.

$$
\mathrm{Nu}_{\text {zone }, j}=0.026 \operatorname{Re}_{\text {zone }, j}^{0.8} \operatorname{Pr}_{\text {zone }, j}^{0.333}\left[\frac{\mu_{\text {gas }, j}\left(T_{\text {zone }, j}\right)}{\mu_{\text {gas }, j}\left(\bar{T}_{\text {wall }}\right)}\right]^{0.14}
$$

where $\mu_{\text {gas }, j}\left(T_{z o n e, j}\right)$ and $\mu_{\text {gas }, j}\left(\bar{T}_{\text {wall }, j}\right)$ are the gas viscosities evaluated at the zone temperature and the average wall temperature in Zone $j$, respectively. Note that the wall temperatures at individual boundary faces in a zone are different and an average wall temperature is used to avoid too many evaluations for the viscosity of the multicomponent gas mixture. Furthermore, with the use of a single average wall temperature, a single convective heat transfer coefficient can be applied to all wall boundary faces in a zone, which reduces the CPU time required to solve the boiler model.

If Reynolds number is less than $10^{4}$, a constant Nusselt number for fully developed laminar flow at uniform surface temperature is used as shown in Eqn. 7 (Incropera and DeWitt, 2002).

$$
\mathrm{Nu}_{z o n e, j}=3.66
$$

Convective heat transfer coefficient for Zone $j h_{c o n v, j}$ can then be calculated from the Nusselt number as shown in Eqn. 8.

$$
h_{\text {conv }, j}=\frac{\mathrm{Nu}_{z o n e, j k_{\text {gas }, j}}}{\bar{D}_{h, j}}
$$

Convective heat transfer flux $q_{c o n v, i}$ from a wall boundary face $i$ to the gas mixture in Zone $j$ can be expressed as

$$
q_{\text {conv }, i}=h_{\text {conv }, j}\left(T_{\text {wall }, i}-T_{z o n e, j}\right)
$$


where $T_{\text {wall, } i}$ is the inner wall temperature of the boundary face, which is solved when convective heat transfer flux is combined with the net radiation heat flux to form the total heat flux as the wall boundary condition for radiative transfer equation (see discussion in Section 2.3.2).

The total heat loss in Zone $j$ due to convection $H_{l, c o n v, j}$ can be calculated by summing up the heat losses of all $N_{f, j}$ boundary wall faces in the zone as shown in Eqn. 10.

$$
H_{l, c o n v, j}=-\sum_{i=0}^{N_{f, j}} q_{c o n v, i} A_{i}
$$

where $A_{i}$ is the surface area of wall boundary face $i . H_{l, c o n v, j}$ is used along with radiation heat loss to enforce energy balance in each zone.

\subsubsection{Radiative Heat Transfer}

The Radiative Transfer Equation (RTE) as shown in Eqn. 11 describes the physics of the radiative heat transfer in a participating medium consisting of a gas mixture and solid particles along the line of sight defined by a solid angle $\Omega$.

$$
\frac{d I(\Omega)}{d l(\Omega)}=-\left(K_{a}+K_{s}\right) I(\Omega)+K_{a} I_{b}+\frac{K_{s}}{4 \pi} \int_{0}^{4 \pi} I(\Omega) \Phi\left(\Omega, \Omega^{\prime}\right) d \Omega^{\prime}
$$

where $I(\Omega), I_{b}$ and $l(\Omega)$ are respectively the radiation intensity, black body emission intensity, and the distance in the direction defined by the solid angle $\Omega . K_{a}$ and $K_{s}$ are the absorption and scattering coefficients of the radiation medium (gases and particles), respectively. $\Phi\left(\Omega, \Omega^{\prime}\right)$ is the phase function for the scattering from $\Omega^{\prime}$ direction to the $\Omega$ direction. The in-scattering term (the last term in Eqn. 11 contains the integration over the $4 \pi$ steradian solid angle. Note that the radiation intensity in Eqn.11 is the total intensity over the entire spectrum of thermal radiation rather than the spectral intensity for a specific wave length. This approach significantly reduces the number of partial differential equations that need to be solved. Since scattering by the gas molecules in the infrared region can be ignored $\left(K_{S} \approx 0\right.$ for the gas phase) and forward scattering by coal particles is dominant $\left(\frac{K_{S}}{4 \pi} \int_{0}^{4 \pi} I(\Omega) \Phi\left(\Omega, \Omega^{\prime}\right) d \Omega^{\prime} \approx K_{S} I(\Omega)\right.$ for the particle phase $)$ in pulverized coal combustion (Mengüç et al., 1994), Eqn. 11 is simplified as

$$
\frac{d I(\Omega)}{d l(\Omega)}=-K_{a} I(\Omega)+K_{a} I_{b}
$$

Both gas and particle phases contribute to the absorption coefficient, and $K_{a}$ is the sum of the gas phase absorption coefficient $K_{a, g}$ and the particle phase absorption coefficient $K_{a, p}$ as shown in Eqn. 13.

$$
K_{a}=K_{a, g}+K_{a, p}
$$


The Planck-mean gas absorption coefficient $K_{a, g}$ is related to local gas emissivity $\epsilon_{g}$ and optical mean beam length $L_{m}$ of the entire flow domain by Eqn. 14 .

$$
K_{a, g}=\frac{-\ln \left(1-\epsilon_{g}\right)}{L_{m}}
$$

To calculate $\epsilon_{g}$, different models can be found in the literature including the Line by Line Model (LBLM), Statistical Narrow Band Model (SNBM), Exponential Wide Band Model (EWBM), and a varieties of Weighted Sum of Gray Gas Models (WSGGMs) (Bordbar et al., 2014). The most accurate method for calculating the emissivity of the gases is the line by line integration which uses spectroscopic databases. However, the spectrum involves millions of absorption lines, which makes the LBLM extremely expensive for radiation modeling. A SNBM such as RADCAL developed at National Institute of Standards and Technology (NIST) (Grosshandler, 1993) performs a few hundred to thousands of spectral evaluations, which reduces the required CPU time by three orders of magnitude and yet generates very accurate results. Since the number of zones in the boiler model is limited and so is the number of function calls to evaluate the gas emissivities, RADCAL is adopted for the boiler model. Six gas species including $\mathrm{O}_{2}, \mathrm{~N}_{2}$, $\mathrm{CH}_{4}, \mathrm{CO}, \mathrm{CO}_{2}$, and $\mathrm{H}_{2} \mathrm{O}$ as well as soot are included in RADCAL, which covers all major absorbing/emitting species involved in fossil fuel combustion. Unlike other simplified curvefitting models such as WSGGMs which are valid only in predefined ranges of gas compositions, the RADCAL model is always valid if the gas mixture mainly consists of the six species included in the model regardless of their mole fractions. Thus it is valid for both air-fired and oxy-fired conditions. In RADCAL, the gas emissivity can be expressed as a function of the mole fractions of individual gas species $x_{i}$, temperature of the gas mixture $T$, total pressure $p$, mean beam length $L_{m}$, and soot volume fraction $f_{v, \text { soot }}$ as shown in Eqn. 15 .

$$
\epsilon_{g}=f\left(x_{\mathrm{O}_{2}}, x_{\mathrm{N}_{2}}, x_{\mathrm{CH}_{4}}, x_{\mathrm{CO}}, x_{\mathrm{CO}_{2}}, x_{\mathrm{H}_{2} \mathrm{O}}, T, p, L_{m}, f_{v, \text { soot }}\right)
$$

The optical mean beam length is related to the total volume of the flow domain $V$ and the total area of boundary faces $F$ by Eqn. 16 .

$$
L_{m}=3.6 \frac{\mathrm{V}}{F}
$$

The soot volume fraction $f_{v, \text { soot }}$ is not solved based on a detailed soot formation and oxidation model. As in one of REI's CFD models (Adams et al., 2013), it is actually estimated as a function of the equivalence ratio of the gas mixture calculated based on the oxidation numbers of individual elements as shown in Eqn. 17.

$$
f_{v, \text { soot }}=f_{E R} x_{C} \frac{\rho_{\text {gas }}}{\rho_{\text {soot }}}
$$

where $x_{C}, \rho_{\text {gas }}$, and $\rho_{\text {soot }}$ are the mass fraction of $\mathrm{C}$ element in the gas mixture, the density of the gas mixture, and the density of soot, respectively. $f_{E R}$ is the fraction of $\mathrm{C}$ in the gas mixture that exists as soot, modeled as a step-wise function of equivalence ratio $E R$ as shown in Eqn. 18. 
In this model, at most $10 \%\left(f_{E R}=0.1\right)$ of available carbon can exist as soot, and when the equivalence ratio $(E R)$ is less than $1\left(\mathrm{O}_{2}\right.$ rich condition), no soot is present.

$$
f_{E R}=\left\{\begin{array}{lr}
0 & E R<1 \\
0.1(E R-1) & 1<E R<2 \\
0.1 & 2<E R
\end{array}\right.
$$

Note that the gas emissivity and absorption coefficient calculated are the mean gray values over the spectrum of interest and are valid only for one mean beam length calculated by Eqn. 16. This approach is the same as those employed by typical CFD models.

The particle absorption coefficient, $K_{a, p}$ in Eqn. 13, is calculated based on the number densities of the particles, their diameters and their average absorption efficiencies over the spectrum. If there are $n$ size ranges of spherical particles, $K_{a, p}$ is expressed as

$$
K_{a, p}=\frac{\pi}{4} \sum_{i=1}^{n} N_{p, i} d_{p, i}^{2} Q_{a, p, i}
$$

where $N_{p, i}, d_{p, i}$, and $Q_{a, p, i}$ are the number density, diameter, and absorption efficiency for size $i$, respectively. The contribution from each particle is based on the projected area $\frac{\pi}{4} d_{p, i}^{2}$. The absorption efficiency $Q_{a, p, i}$ of a particle containing char (the organic part) and ash (the inorganic or mineral part) is modeled as the weighted average based on the mass fractions of char and ash as shown in Eqn. 20.

$$
Q_{a, p, i}=y_{c h a r} Q_{a, p, i, c h a r}+y_{a s h} Q_{a, p, i, a s h}
$$

where $Q_{a, p, i, c h a r}$ and $Q_{a, p, i, a s h}$ are the absorption efficiencies for the char only and ash only particles with the same diameter as the modeled particle of size $i$, respectively. $y_{c h a r}$ and $y_{a s h}$ are the mass fractions for the char and the ash in the particle. The spectral absorption efficiencies of a char only and an ash only particle at discretized diameters and temperatures are calculated based on Mie theory (Mie, 1908; Hulst, 1981) for spherical particles with the complex indices of refraction of char and ash as functions of temperature and wave length reported in the literature (e.g. Mengüç et al., 1994; Modest, 2013). It is assumed that any change in gas composition or firing configuration does not affect the complex indices of refraction of the char and ash in the particle phase and, hence, the absorption efficiencies calculated are valid for both air-fired and oxy-fired conditions. Experimental measurements on complex indices of the char and ash formed in oxy-combustion environment need to be made or studied to verify this assumption. The average absorption efficiency over the radiation spectrum is taken as the mean of the Plank and Rosseland averages calculated by convoluting over the entire spectrum with 5000 wavelength intervals. Note that the convolution over the entire spectrum is needed since the total radiation intensity of the RTE (Eqn. 12) is solved, rather than the RTEs for individual wavelengths (spectral form). To speed up the average absorption efficiency calculation, lookup tables of $Q_{a, p, i, c h a r}$ and $Q_{a, p, i, a s h}$ for char and ash particles, respectively, as functions of particle 
diameter and temperature are created in the initialization stage of the boiler model. Linear interpolation is made during the iterative radiation calculations based on the lookup tables.

The number density $N_{p, i}$ for a particle size range in Eqn. 19 is obtained through the Lagrangian particle phase tracking algorithm (see Section 2.3.3). In this algorithm, each particle injection from a particle starting location (e.g. a coal burner) contributes to the particle number density in the zone that the particles pass through and hence to the particle absorption coefficient of the zone. If the number flow rate of the particles represented by the trajectory is $\dot{N}_{p, i}$, the residence time is $t_{z o n e}$ and the volume of the zone the particles travel through is $V_{z o n e}$, the number density contributed by the trajectory can be described as shown in Eqn. 21.

$$
N_{p, i}=\frac{\dot{N}_{p, i} t_{\text {zone }}}{V_{\text {zone }}}
$$

$K_{a, p}$ in Eqn. 19 is a cumulative quantity, meaning that its final value can be obtained by successive addition of individual contributors. The particle absorption coefficient for a zone can be calculated by summing up the contributions by the particle injections from multiple starting locations.

Boundary conditions for the RTE (Eqn. 12) are similar to those in typical CFD models (Ma et al., 2012) and are briefly described below.

The wall of a radiant furnace is assumed to be gray and diffuse (Assumption 7). At the wall boundary, the incident heat flux towards the wall surface can be calculated by integrating over the $2 \pi$ steradian solid angle of the hemisphere towards the wall face. For example, in a spherical coordinate system, the incident radiation heat flux $q_{\text {rad,inc }}$ can be calculated from the radiation intensity $I(\theta, \phi)$ along the azimuthal and polar angles.

$$
q_{\text {rad,inc }}=\int_{0}^{2 \pi} I(\Omega) d \Omega=\int_{0}^{2 \pi}\left[\int_{0}^{\frac{\pi}{2}} I(\theta, \phi) \sin \phi \cos \phi d \phi\right] d \theta
$$

where $\theta$ and $\phi$ are azimuthal and polar angles, respectively. Note that if the radiation intensity is isotropic (uniform in any directions), the incident heat flux integrated from Eqn. 22 will be $\pi I$. With the DO method adopted in the boiler model, Eqn. 22 can be evaluated as a summation over the intensities and angles of all discrete ordinates in the hemisphere with respect to the normal direction of a boundary face using the weighting factors for individual directions.

A gray and diffuse wall with an emissivity $\epsilon_{w}$ is able to emit radiation and reflect part of the incident radiation. The sum of the emitted and reflected radiation heat flux is computed as

$$
q_{r a d, o u t}=q_{r a d, i n c}\left(1-\epsilon_{w}\right)+\epsilon_{w} \sigma T_{w}^{4}
$$


where $\sigma$ is the Stefan-Boltzmann constant $\left(5.67 \times 10^{-8} \mathrm{~W} / \mathrm{m}^{2}-\mathrm{K}^{4}\right)$. No transmission through the wall is considered in Eqn. 23. The net flux of radiation heat transferred from the wall to the flow domain is

$$
q_{\text {rad,net }}=q_{\text {rad,out }}-q_{\text {rad,inc }}
$$

The net radiation flux $q_{\text {rad,net }}$ from the wall to the gas-solid mixture in the furnace is combined with convective heat transfer flux from Eqn. 9 to calculate the wall temperature $T_{w}$ based on Eqn. 25.

$$
q_{\text {rad,net }}+q_{\text {conv }}=\frac{\left(T_{\text {fluid }}-T_{w}\right)}{r_{w}}
$$

where $T_{\text {fluid }}, T_{w}$, and $r_{w}$ are respectively the temperature of the fluid (liquid water or steam) inside the wall tube, the slagging layer wall temperature, and the overall heat transfer resistance including heat conduction through the slagging layer and metal wall and convective heat transfer between the inner tube wall and the fluid inside the wall tube. Combining Eqns. 9 and 23-25, the wall temperature can be obtained by solving Eqn. 26 if the incident radiation heat flux $q_{\text {rad,inc }}$ and convective heat transfer coefficient $h_{\text {conv }}$ are provided from previous iteration step or initial guess.

$$
r_{\text {wall }} \epsilon_{w}\left(\sigma T_{w}^{4}-q_{\text {rad,inc }}\right)+\left(1-h_{\text {conv }}\right) T_{w}+\left(h_{\text {conv }}-1\right) T_{\text {fluid }}=0 \quad \text { Eqn. } 26
$$

After the wall temperature is determined, the heat flux of radiation leaving the wall to the flow domain $q_{\text {rad,out }}$ can be calculated by Eqn. 23 . For a diffuse wall, the isotropic outward radiation intensity $I_{w, o u t}$ can then be calculated as

$$
I_{w, \text { out }}=\frac{q_{\text {rad,out }}}{\pi}
$$

This intensity is the wall boundary condition of the RTE (Eqn. 12) for the next iteration. The solution of the DO method is considered converged if the intensity at the boundary calculated for the next iteration is within tolerance $\varepsilon_{t o l}$ of the current iteration.

For the model exit boundary, the temperature $T_{w}$ and emissivity $\epsilon_{w}$ of the walls facing the exit plane are generally specified as user inputs. $q_{\text {rad,out }}$ of Eqn. 23 can be calculated directly since the backside wall temperature is given as a user input. Therefore, radiation intensity can be calculated based on Eqn. 27 as the boundary condition for next iteration. Net radiation heat flux leaving the exit plane, if any, should be added to the downstream heat transfer surfaces. Depending on the area of the exit plane and the temperature of the downstream walls, the net radiation heat loss at the model exit could be as high as 5\% of the total heat loss to the boundary walls. 
After the radiation intensity in the radiative transfer equation is solved, the irradiance $G$ at a point inside the flow domain can be calculated from the radiation intensity $I(\Omega)$ by integration over the $4 \pi$ steradian solid angle.

$$
G=\int_{0}^{4 \pi} I(\Omega) d \Omega
$$

When the radiation intensities are solved in discrete ordinates (directions) of the $4 \pi$ solid angle in the boiler model, the integration in Eqn. 28 is calculated by summing up the products of radiation intensity $I_{k}$ and the corresponding weight $w_{k}$ of an ordinate $k$ over $N$ discrete ordinates.

$$
G=\sum_{k=1}^{N} I_{k} w_{k}
$$

The sum of all the weights of the $N$ discrete ordinates is $4 \pi$.

$$
\sum_{k=1}^{N} w_{k}=4 \pi
$$

The radiation heat loss per unit volume of Cell $i$ is the flux divergence considering both the absorption and emission of the participating medium and can be calculated as

$$
h_{l, r a d, i}=4 \pi K_{a} I_{b}-K_{a} G=4 \pi K_{a} \frac{\sigma T_{z o n e, j}^{4}}{\pi}-K_{a} G=4 \sigma K_{a} T_{z o n e, j}^{4}-K_{a} G \quad \text { Eqn. } 31
$$

where $T_{z o n e, j}$ is the gas and particle mixture temperature of Zone $j$ to which Cell $i$ belongs. The heat loss of a 3-D cell due to radiative heat transfer can be calculated by multiplying $h_{l . r a d, i}$ by the cell volume and the total heat loss in a zone can be calculated by summing up the radiation heat losses of all cells in the zone as shown in Eqn. 32.

$$
H_{l, r a d, j}=\sum_{i=1}^{N_{c e l l, j}}\left(h_{l, r a d, i} V_{c e l l, i}\right)
$$

where $H_{l, r a d, j}$ is radiation heat loss of Zone $j, h_{l, r a d, i}$ and $V_{c e l l, i}$ are the heat loss per unit volume and the volume of Cell $i$ in Zone $j$, respectively. The summation is over the total number of cells $N_{c e l l, j}$ in Zone $j$. Note that the total heat loss in a zone includes the radiation heat loss from all cells in the zone and the convective heat loss from all wall boundary faces in the zone.

$$
H_{l, t o t a l, j}=H_{l, r a d, j}+H_{l, c o n v, j}
$$

where the convective heat loss $H_{l, c o n v, j}$ is calculated by Eqn. 10. This heat loss term for the zone is used to calculate the enthalpy of the gas and solid mixture leaving the zone (see Section 2.3.5).

\subsubsection{Lagrangian Particle Tracking}

Pulverized coal particles are carried by primary gas streams and fed to a boiler through coal burners installed at different locations. Upon injection, a coal particle undergoes moisture vaporization, devolatilization, and char oxidation and gasification processes. During those 
processes, the elements contained in the parent coal, mainly $\mathrm{C}, \mathrm{H}, \mathrm{O}, \mathrm{N}$, and $\mathrm{S}$, are released to the gas phase in the form of water vapor, volatile species, and the products of char/gas heterogeneous reactions. The size, temperature, composition and radiative properties of the particle change along its trajectory. Mass, momentum, and energy, including the radiation energy are exchanged between the particle and its surrounding gases. The Lagrangian particle tracking method is used in the boiler model to account for the exchange between the discrete particle and gas phases. This approach is similar to the Lagrangian discrete phase model (DPM) approach adopted by many CFD software packages. The advantage of using Lagrangian framework over Eulerian framework for discrete particle phase simulation is the fact that it can resolve the particle history related to the changes of particle size, composition (coal, char and ash) and radiation properties and it also predicts the contributions of unburned carbon from different burner inlets.

Figure 3 illustrates the vertical movement of a coal particle in a section of a boiler divided by three zones (Zones $j-1, j, j+1$ ) along the boiler height. Here the exact location of a particle in Cartesian coordinates, its velocity, and its acceleration are not calculated as they are in a typical CFD code. Instead, only the upward movement of the particle from one zone to another is tracked. The trajectory illustrated here represents the trajectory of a particle of an initial diameter injected from a specific burner location. Since coal particles from a pulverizer have different sizes, multiple size ranges are used to model the particle size distribution. Each size range is associated with an average particle diameter and a mass fraction. Therefore, multiple trajectories are calculated from each burner or each starting location, one for each particle size range. Each particle trajectory of size $i$ from a burner has a particle number flow rate $\dot{N}_{p, i}$ calculated from the total coal flow rate of the burner $\dot{m}_{\text {burner }}$ and the particle size distribution.

$$
\dot{N}_{p, i}=\frac{f_{\text {mass }, i} \dot{m}_{\text {burner }}}{m_{p, o, i}}
$$

where $f_{\text {mass }, i}$ is the mass fraction of particles in size range $i$, and $m_{p, o, i}$ is the initial particle mass of that size, which is related to the initial particle diameter $d_{p, o, i}$ and initial particle density $\rho_{p, o}$ as shown in Eqn. 35.

$$
m_{p, o, i}=\frac{1}{6} \pi d_{p, o, i}^{3} \rho_{p, o}
$$

The particle number flow rate $\dot{N}_{p, i}$ in Eqn. 34 is used to calculate the mass release and radiation properties (see Eqn. 21). 


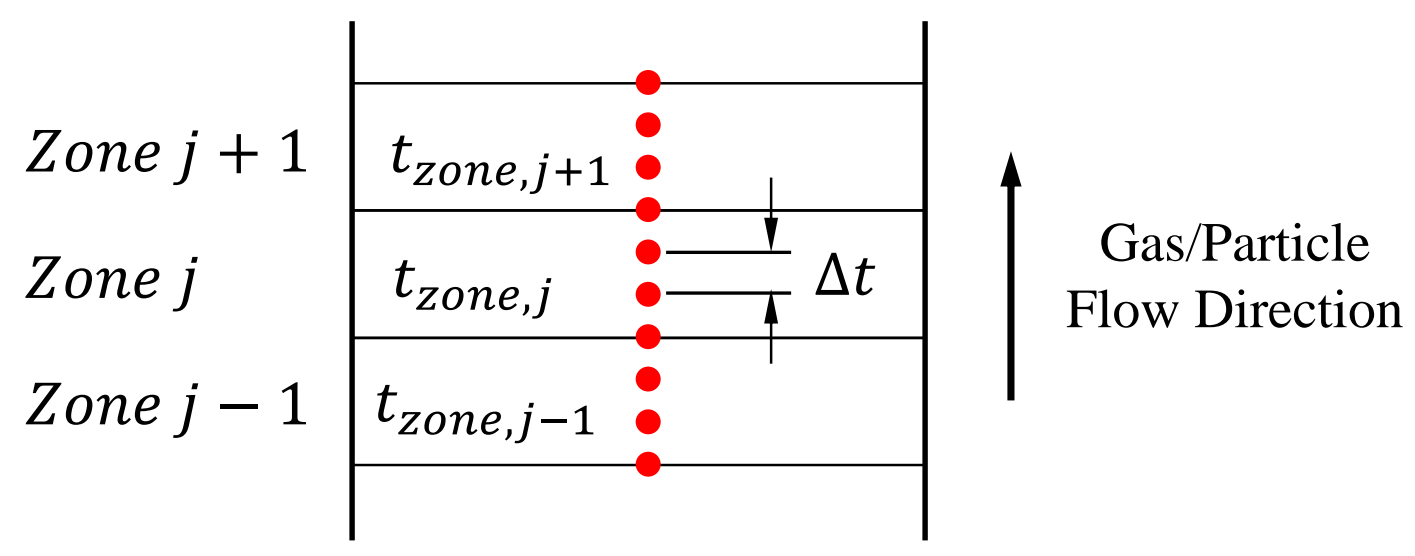

Figure 3. Lagrangian particle tracking approach

Based on Assumption 3, the vertical velocity of all particles in a zone is the same as the vertical velocity of the gas mixture in the zone. In other words, the residence time of a particle in Zone $j$ is assumed to be the same as the residence time of the gas phase $t_{z o n e, j}$ calculated based on the volume of the zone $V_{z o n e, j}$ and the volumetric flow rate of the gas leaving the zone $\dot{V}_{g a s, j}$ as shown in Eqn. 36.

$$
t_{\text {zone }, j}=\frac{V_{\text {zone }, j}}{\dot{V}_{\text {gas }, j}}=\frac{\rho_{\text {gas }, j} V_{\text {zone }, j}}{\dot{m}_{\text {gas }, j}}
$$

$\dot{V}_{g a s, j}$ can be calculated from the mass flow rate of the gas $\dot{m}_{g a s, j}$ and the density of the gas in the zone $\rho_{g a s, j}$. In case the particle starting location is at a vertical location between the bottom and the top of the zone, the residence time of the particle is proportional to the vertical distance between the top of the zone and the starting location.

Multiple time steps are used for each zone to track the particle reactions, property changes, and the exchange of mass with the gas phase as shown in Figure 3. Typically the time step $\Delta t$ is $1 \%$ of the residence time of the zone. Smaller time steps result in more accurate model prediction but longer CPU time.

\subsubsection{Moisture Vaporization, Coal Devolatilization and Heterogeneous Char Reactions}

According to Assumption 5, moisture vaporization and coal devolatilization occur immediately upon a coal particle's entry to the boiler. The mass of the fresh char particle $m_{p, f}$ upon the completion of the moisture vaporization and coal devolatilization can be expressed as:

$$
m_{p, f}=m_{p, o}\left(1-y_{\text {moisture }}-y_{v o l}\right)
$$

where $m_{p, o}$ is the mass of the original coal particle, $y_{\text {moisture }}$ is the mass fraction of moisture in the original coal particle, and $y_{v o l}$ is the volatile content (mass fraction) in the original coal particle. To avoid complexity, the subscript for particle size range is dropped here. During coal devolatilization, the diameter of a coal particle could increase slightly, which is known as 
particle swelling. The swelling factor, defined as the fraction of the increase in particle diameter from the original diameter, depends on the coal type. The diameter of a fresh char particle after the completion of devolatilization $d_{p, f}$ is related to the swelling factor $f_{\text {swell }}$ and original diameter $d_{p, o}$ by

$$
d_{p, f}=d_{p, o}\left(1+f_{\text {swell }}\right)
$$

The density of a fresh char particle $\rho_{p, f}$ can be calculated by the mass of the char particle from Eqn. 37 and the diameter from Eqn. 38.

$$
\rho_{p, f}=\frac{6 m_{p, f}}{\pi d_{p, f}^{3}}
$$

After the moisture and the volatiles are released, the remaining char particle undergoes heterogeneous reactions with reactants in the gas phase including $\mathrm{O}_{2}, \mathrm{H}_{2} \mathrm{O}$ and $\mathrm{CO}_{2}$. The reaction with $\mathrm{O}_{2}$ is known as the oxidation or combustion reaction and the reactions with $\mathrm{H}_{2} \mathrm{O}$ and $\mathrm{CO}_{2}$ are known as gasification reactions. During the heterogeneous reactions, the char particle shrinks and its density decreases. Eqn. 40 relates particle density $\rho_{p}$ to particle mass $m_{p}$ during heterogeneous char reactions.

$$
\frac{\rho_{p}}{\rho_{p, f}}=\left(\frac{m_{p}}{m_{p, f}}\right)^{\alpha}
$$

where exponent $\alpha$ is called the burning mode parameter (Hurt, 1992). From Eqn. 40, the diameter of the char particle can be expressed as

$$
\frac{d_{p}}{d_{p, f}}=\left(\frac{m_{p}}{m_{p, f}}\right)^{\frac{1-\alpha}{3}}
$$

The diameter calculated by Eqn. 41 is used to obtain the radiation absorption efficiencies of organic only char particles and ash only particle from the lookup table and then the average absorption efficiency of the particle based on Eqn. 20.

Three heterogeneous reactions including char oxidation by $\mathrm{O}_{2}$, and char gasification by $\mathrm{H}_{2} \mathrm{O}$ and $\mathrm{CO}_{2}$ are considered in the boiler model, each of which can be expressed in a general form as shown below.

$$
\mathrm{C}+v_{R, i} \mathrm{R}_{i} \rightarrow v_{P 1, i} \mathrm{P}_{1, i}+v_{P 2, i} \mathrm{P}_{2, i}
$$

where $\mathrm{R}_{i}, \mathrm{P}_{1, i}$, and $\mathrm{P}_{2, i}$ are the gas reactant and the two gas products of Reaction $i$, respectively. The corresponding stoichiometric coefficients are $v_{R, i}, v_{P 1, i}$ and $v_{P 2, i}$. Table 1 lists the reactants, products, and the stoichiometric coefficients for the three heterogeneous reactions included in the boiler model. 
Table 1. Reactant, products of char heterogeneous reactions and their stoichiometric coefficients

\begin{tabular}{|c|c|c|c|c|c|c|}
\hline Reaction & $\mathrm{R}_{i}$ & $\mathrm{P}_{1, i}$ & $\mathrm{P}_{2, i}$ & $v_{R, i}$ & $v_{P 1, i}$ & $v_{P 2, i}$ \\
\hline 1 & $\mathrm{O}_{2}$ & $\mathrm{CO}_{2}$ & $\mathrm{CO}$ & $\frac{2+\psi}{2(1+\psi)}$ & $\frac{1}{1+\psi}$ & $\frac{\psi}{1+\psi}$ \\
\hline 2 & $\mathrm{H}_{2} \mathrm{O}$ & $\mathrm{H}_{2}$ & $\mathrm{CO}$ & 1 & 1 & 1 \\
\hline 3 & $\mathrm{CO}_{2}$ & $\mathrm{CO}$ & N/A & 1 & 2 & 0 \\
\hline
\end{tabular}

Note that the char oxidation reaction (Reaction 1 in Table 1) could form both $\mathrm{CO}_{2}$ and $\mathrm{CO}$ as the products. The ratio of the stoichiometric coefficients of $\mathrm{CO}_{2}$ to $\mathrm{CO}$ is defined as parameter $\psi$, which can be expressed as an Arrhenius function of particle temperature as shown in Eqn. 43.

$$
\psi=A_{\psi} e^{-\frac{E_{\psi}}{R T}}
$$

where $A_{\psi}, E_{\psi}$, and $T$ are the pre-exponential factor, activation energy, and particle temperature, respectively. $R$ in Eqn. 43 is the universal gas constant. Based on Assumption 4, the particle temperature is the same as the temperature of the zone the particle travels through.

The bulk flow is outward for char reactions. The net outward molar flow per kmole of $\mathrm{C}$ reacted for Reaction $i$ can be expressed as

$$
v_{n e t, i}=v_{P 1, i}+v_{P 2, i}-v_{R, i}
$$

The heterogeneous reaction rate can be expressed in a global rate form based on the unit external surface area for Reaction $i$ as

$$
r_{C, i}^{\prime \prime}=A_{i} T^{b_{i}} e^{-\frac{E_{i}}{R T}} C_{R, i, S}^{n_{i}}
$$

where $r_{C, i}^{\prime \prime}$ is the reaction rate in $\mathrm{kmol}-\mathrm{C} / \mathrm{m}^{2} \mathrm{~s}$ and the double prime $\left({ }^{\prime \prime}\right)$ indicates the rate is relative to a unit external surface area. $A_{i}$ and $E_{i}$ in Eqn. 45 are the pre-exponential factor and the activation energy for Reaction $i . b_{i}$ is the exponent of temperature and $n_{i}$ is the reaction order. $C_{R, i, S}$ is the molar concentration of gas reactant at the external surface of the particle, which is related to mole fraction of the reactant $x_{R, i, s}$ and total molar concentration of the gas mixture $C_{t}$, which can be calculated from total pressure $P_{t}$ based on ideal gas law.

$$
C_{R, i, s}=C_{t} x_{R, i, s}=\frac{P_{t}}{R T} x_{R, i, s}
$$

The half-order char oxidation reaction model reported by Hurt and Mitchell (1992) is used to model the first heterogeneous reaction in Table 1 along with their $\mathrm{CO}_{2}$ to $\mathrm{CO}$ stoichiometric coefficient ratio model (Eqn. 43). First-order kinetic models are used for the char 
gasification reactions by $\mathrm{H}_{2} \mathrm{O}$ and $\mathrm{CO}_{2}$. Table 2 shows the temperature exponents and reaction orders for the three char reactions modeled.

Table 2. Temperature exponent and reaction order for char heterogeneous reactions

\begin{tabular}{|c|c|c|c|}
\hline Reaction & Gas Reactant & Temperature Exponent $b_{i}$ & Reaction Order $n_{i}$ \\
\hline 1 & $\mathrm{O}_{2}$ & 0.5 & 0.5 \\
\hline 2 & $\mathrm{H}_{2} \mathrm{O}$ & 1 & 1 \\
\hline 3 & $\mathrm{CO}_{2}$ & 1 & 1 \\
\hline
\end{tabular}

To calculate the rates of the three reactions, film diffusion needs to be considered. Figure 4 shows the mass transfer of the reactant and product species around a single char particle.

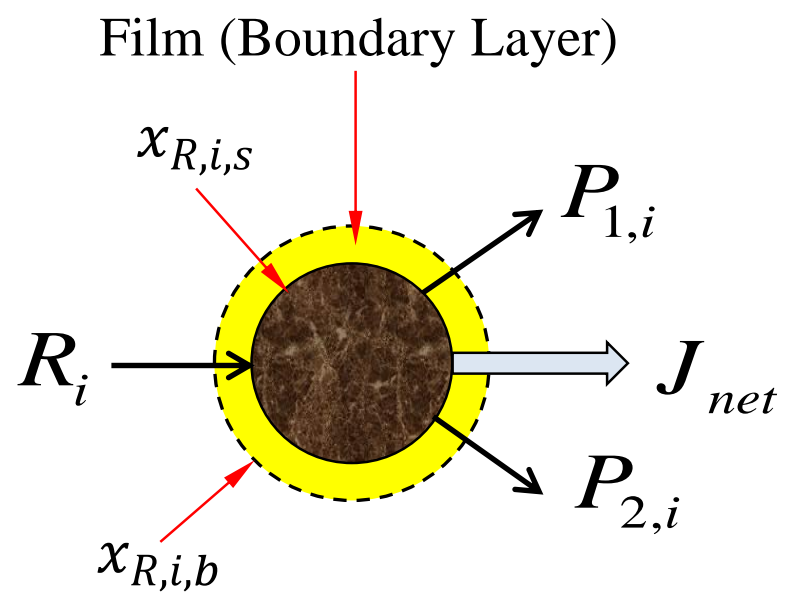

Figure 4. Species mass transfer around a char particle

For Reaction $i$, the mole fraction of the reactant at external surface of a char particle $x_{R, i, s}$ is usually lower than that in the bulk of the gas mixture $x_{R, i, b}$. If the reaction is kinetically controlled, they are very close to each other. If the reaction is diffusion controlled, the surface mole fraction will be very close to zero. For the intermediate case where both the film diffusion and kinetics are important, the surface mole fraction $x_{R, i, s}$ needs to be solved by the stoichiometric relationship between the solid reactant (assumed as element $\mathrm{C}$ as in Eqn. 42) and the gas reactant.

$$
J_{R, i}=v_{R, i} r_{C, i}^{\prime \prime}
$$

where $J_{R, i}$ is the molar flux of gas reactant of Reaction $i$ reached to the particle surface through mass transfer. $J_{R, i}$ can be expressed as

$$
J_{R, i}=k_{x, i}\left(x_{R, i, b}-x_{R, i, s}\right)-x_{R, i, S} J_{n e t}
$$


where $k_{x, i}$ is the mole fraction based mass transfer coefficient. The first term on the right hand side of Eqn. 48 accounts for the diffusion of the gas reactant from the bulk gas mixture stream to the particle's external surface and the second term accounts for the effect of convection due to net outward flow from the particle to the bulk stream. $J_{n e t}$ is the net outward molar flux of gas species leaving the char particle due to the three reactions.

$$
J_{\text {net }}=\sum_{i=1}^{3} \frac{J_{R, i} v_{n e t, i}}{v_{R, i}}
$$

$k_{x, i}$ in Eqn. 48 can be calculated from the uncorrected concentration based mass transfer coefficient $k_{c, i}$ and a correction factor due to high mass transfer rate $f_{b, i}$, also known as blowing factor.

$$
k_{x, i}=f_{b, i} C_{t} k_{c, i}
$$

Based on film theory (Bird et al., 1960), the blowing factor $f_{b, i}$ is related to the flux ratio $\phi_{i}$ by

$$
f_{b, i}=\frac{\phi_{i}}{1-e^{\phi_{i}}}
$$

and the flux ratio is defined as

$$
\phi_{i}=\frac{J_{n e t}}{C_{t} k_{c, i}}
$$

The concentration based mass transfer coefficient $k_{c, i}$ can be calculated from the Sherwood number, which is approximately equal to 2 when slip velocity between the particle and the gas mixture is ignored. Therefore,

$$
k_{c, i}=\frac{2 D_{i, m}}{d_{p}}
$$

where $D_{i, m}$ is the molecular diffusivity of the gas reactant $R_{i}$ of Reaction $i$ in the gas mixture and $d_{p}$ is the particle diameter. As an approximation, the diffusivity of the reactant $\left(\mathrm{O}_{2}, \mathrm{H}_{2} \mathrm{O}\right.$, or $\mathrm{CO}_{2}$ ) in $\mathrm{N}_{2}$ is used in the boiler model to avoid calculating the diffusivities of all the pairs in the mixture. The errors caused by this simplification needs to be investigated especially in oxycombustion conditions.

Combining Eqns. 45-48, the equation for solving the surface mole fraction of the gas reactant $R_{i}$ of Reaction $i$ can be expressed as

$$
v_{R, i} A_{i} T^{b_{i}} e^{-\frac{E_{i}}{R T} C_{t}^{n_{i}}} x_{R, i, S}^{n_{i}}=k_{x, i}\left(x_{R, i, b}-x_{R, i, s}\right)-x_{R, i, S} J_{n e t}
$$

Note that at a given $J_{n e t}$, the blowing factor $\phi_{i}$ and mass transfer coefficient $k_{x, i}$ can be calculated based on Eqns. 50-53 and then the surface mole fraction $x_{R, i, s}$ in Eqn. 54 can be solved. Since $J_{\text {net }}$ is unknown a priori, an iterative procedure has to be used. Initially it is set to 
zero and then the surface mole fractions of three gas reactants are solved followed by the calculation of $J_{R, i}$ and $J_{\text {net }}$. The new $J_{n e t}$ is used thereafter until a converged solution is reached, usually within 3 iterations.

Finally, the char reaction rate is calculated, in terms of mass loss per particle per time, after $r_{C, i}^{\prime \prime}$ for each reaction is calculated, i.e.,

$$
\frac{d m_{p}}{d t}=-\pi d_{p}^{2} M_{w, c} \sum_{i=1}^{3} r_{C, i}^{\prime \prime}
$$

where $M_{w, c}$ is the molecular weight of carbon (C). Note that the char heterogeneous reaction model described above is formulated based on carbon, the dominant element in char. It is assumed that the other elements are released in the same rate as carbon such that the elemental composition of the unburned char is identical to that of the fresh char. Moreover, the derivations for the heterogeneous reaction rates are based on the assumption that the gas reactant mole fractions are uniform in each zone (Assumption 1). In case some local fluid dynamics structures (e.g. a turbulent diffusion coal flame) extend to multiple zones, the gas composition in each zone will deviate from the uniform assumption to certain extent. To consider the deviation from the assumption, an effectiveness factor (usually less than 1) is applied to the mole fraction of a reactant. The bulk mole fraction $x_{R, i, b}$ in Eqns. 48 and 54 is adjusted as.

$$
x_{R, i, b}=f_{\text {mixedness }} x_{R, i, b, e q}
$$

Eqn. 56

where $f_{\text {mixedness }}$ is the effectiveness factor to account for the "mixedness" between the gas reactant for Reaction $i$ and the particle phase and $x_{R, i, b, e q}$ is the mole fraction of the reactant obtained from the gas phase equilibrium calculation to be discussed next. The user is allowed to specify different effectiveness factors for individual zones and the default value of $f_{\text {mixedness }}$ is 1 , corresponding to a well-mixed case.

\subsubsection{Gas Phase Chemistry}

Based on Assumption 2, the gas phase reactions in each zone are assumed to be fast so that they reach chemical equilibrium. The temperature and mole fractions of individual species in the gas phase are calculated by minimizing the Gibbs free energy of the system. Twelve species are considered in the chemical equilibrium calculation, namely, $\mathrm{Ar}, \mathrm{C}, \mathrm{O}_{2}, \mathrm{~N}_{2}, \mathrm{H}_{2}, \mathrm{CO}$, $\mathrm{CO}_{2}, \mathrm{H}_{2} \mathrm{O}, \mathrm{SO}_{2}, \mathrm{H}_{2} \mathrm{~S}, \mathrm{HCl}$, and $\mathrm{CH}_{4}$. Seven elements are involved, namely, C, H, O, N, S, Cl, and $\mathrm{Ar}$. Note that $\mathrm{Cl}$ in solid fuel and $\mathrm{HCl}$ in gas mixture are include to handle other solid fuels such as biomass. To perform chemical equilibrium calculations, enthalpy and elemental composition of the gas stream leaving each zone are required. $\dot{m}_{e, j, t o t a l}$ is the total mass flow rate of Element $e$ contained in the gas/solid mixture that leaves Zone $j . \quad \dot{m}_{e, j, t o t a l}$ can be calculated from the elemental flow rates of the feed streams below the top plane of Zone $j$ as shown in Eqn. 57. 


$$
\dot{m}_{e, j, t o t a l}=\sum_{k=1}^{N_{j, f e e d}} \dot{m}_{e, k}
$$

where $\dot{m}_{e, k}$ is the mass flow rate of Element $e$ from feed stream $k$ and $N_{j, f e e d}$ is the number of feed streams below the top horizontal plane of Zone $j$.

The mass flow rate of Element $e$ in the gas stream that leaves Zone $j$ is simply the total mass flow rate of the element calculated by Eqn. 57 minus the flow rate of Element $e$ in the solid phase $\dot{m}_{e, j, s o l i d}$ calculated by the particle tracking model described in the previous section.

$$
\dot{m}_{e, j, g a s}=\dot{m}_{e, j, t o t a l}-\dot{m}_{e, j, s o l i d}
$$

Likewise, the enthalpy flow rate for the gas/solid mixture leaving Zone $j$ is the sum of the enthalpy flow rates of the gas and solid feed streams that enter below the top plane of Zone $j$ minus the sum of the total heat losses from those zones as shown in Eqn. 59.

$$
\dot{m}_{j, \text { gas }} h_{j, \text { gas }}+\dot{m}_{j, \text { solid }} h_{j, \text { solid }}=\sum_{k=1}^{N_{j, f e e d}} \dot{m}_{k} h_{k}-\sum_{l=1}^{j} H_{l, t o t a l, l}
$$

where $\dot{m}_{j, g a s}$ and $h_{j, g a s}$ are respectively the mass flow rate and mass based enthalpy of gas mixture leaving Zone $j$ whereas $\dot{m}_{j, \text { solid }}$, and $h_{j, \text { solid }}$ are, respectively, the mass flow rate and mass based enthalpy of the solid phase material leaving the zone. $\dot{m}_{k}$ and $h_{k}$ in Eqn. 59 are the mass flow rate and the mass based enthalpy of feed stream $k$, respectively. $N_{j, f e e d}$ in Eqn. 59 is the number of feed streams below the top plane of Zone $j . H_{l, \text { total, } l}$ in Eqn. 59 is the total heat loss (radiation and convection) in Zone $l$ that is below the top plane of Zone $j$.

The local chemical equilibrium calculation in the gas phase of each zone is carried out using the Lagrange multiplier method with mass conservation for each element as constraints. The gas mixture is assumed to be an ideal gas mixture with partial molar Gibbs free energy $\bar{G}_{i}\left(T, p, x_{i}\right)$ of a species as a function of the Gibbs free energy of the pure species $G_{i}(T, p)$ and the mole fraction of the species in the mixture $x_{i}$ as shown in Eqn. 60.

$$
\bar{G}_{i}\left(T, p, x_{i}\right)=G_{i}(T, p)+R T \ln x_{i}
$$

The mole fraction of species $i$ is related to the specific mole $n_{i}$ defined as the kmoles of species $i$ in $1 \mathrm{~kg}$ of gas mixture.

$$
x_{i}=\frac{n_{i}}{\sum_{i=1}^{n_{s}} n_{i}}
$$

where $n_{s}$ is the total number of gas species in the gas mixture $\left(n_{s}=12\right.$ for the boiler model). The total Gibbs free energy of the gas mixture can be calculated as

$$
G=\sum_{i=1}^{n_{S}}\left[\bar{G}_{i}\left(T, p, n_{i}\right) n_{i}\right]
$$


To solve for chemical equilibrium, the Gibbs free energy of the gas mixture shown in Eqn. 62 is minimized subject to the constraints of element conservation as shown in Eqn. 63.

$$
n_{e}=\sum_{i=1}^{n_{s}}\left[\beta_{e, i} n_{i}\right]
$$

where $\beta_{e, i}$ is the number of atoms of element $e$ in a molecule of species $i$ and $n_{e}$ is the kmoles of atoms of Element $e$ in $1 \mathrm{~kg}$ of the gas mixture, which can be calculated from Eqn. 58 and the atomic mass of Element $e$.

Gas phase equilibrium calculations are performed for the gas mixture leaving each zone at defined temperature $T$ and pressure $p$, which is the user specified boiler operating pressure. Temperature $T$ is solved iteratively such that the enthalpy conservation based on Eqn. 59 for gas and solid mixture is satisfied.

\subsection{Boiler Model Solution Procedure}

The equations listed in Section 2.3 are solved numerically in the boiler model. Figure 5 shows the procedure of the numerical algorithms. 


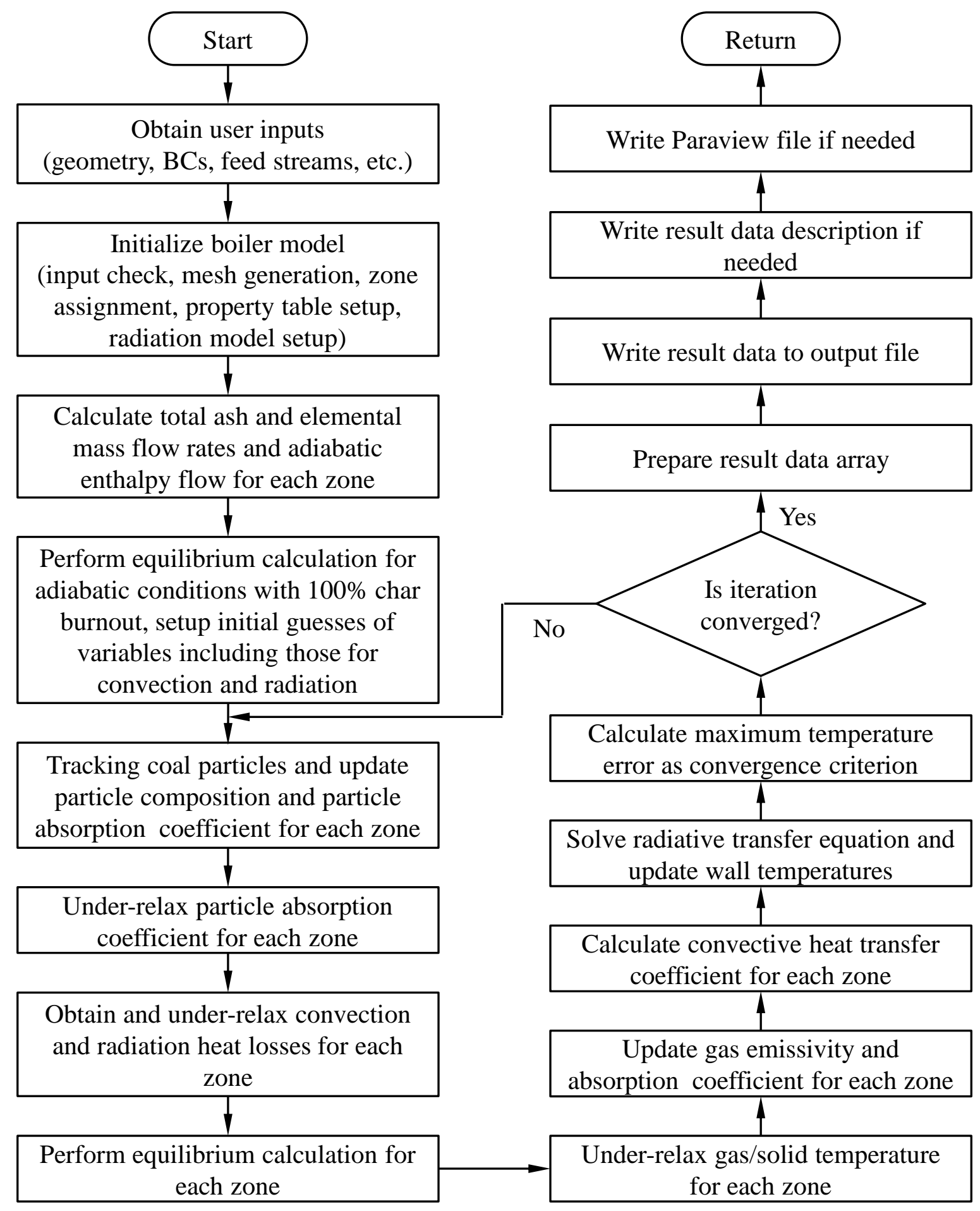

Figure 5. Numerical solution procedure for the boiler model

The boiler model program starts by reading the user inputs regarding boiler geometry, boundary conditions, feed stream data, and zone/mesh discretization options followed by a model initialization step in which user inputs are checked, the 3-D mesh is generated with 
individual cells assigned to 1-D zones, and the particle radiation absorption coefficient tables for char and ash are set up. Then the mass flow rates of individual elements leaving each zone (Eqn. 57) are calculated along with the enthalpy flow rate for each zone ignoring the heat loss (the first term on the right side of Eqn. 59). After setting up the initial guesses for the variables based on complete char burnout and adiabatic reactions, the program enters an iteration loop in which some model variables are updated, under-relaxed, and finally converged. The under-relaxation is a strategy widely used in CFD software to converge a solution to highly non-linear equations by updating a variable to be solved iteratively as the weighted sum of the new value solved in the current iteration and the old value solved in the previous iteration. If $\phi_{\text {new }}$ and $\phi_{\text {old }}$ are the values of a variable solved in the current and previous iterations, respectively, the under-relaxed value $\phi$ is calculated as

$$
\phi=\lambda \phi_{\text {new }}+(1-\lambda) \phi_{\text {old }}
$$

where $\lambda$ is the under-relaxation factor $(0<\lambda<1)$. The iteration loop of the boiler model starts from the Lagrangian tracking of coal particles from each feed stream and each size range through the zones along their path to furnace exit. During the tracking process, the remaining mass of each particle is calculated in multiple time steps based on the char reaction kinetics and mass transfer, and the diameter of the particle as well as its radiation properties are updated. After all particles from different feed streams and different size ranges are tracked, the amount of the unburned dry-ash-free part of the particles in each zone is updated as is the particle absorption coefficient of the zone. They are under-relaxed to avoid the oscillation from one iteration to another. The convective and radiative heat losses calculated for each zone from the solution of the discrete radiative transfer equation coupled with convective heat transfer at wall faces are also under-relaxed. The under-relaxed total heat loss is used to calculate the actual enthalpy of the gas-solid mixture leaving each zone. Chemical equilibrium calculations are then performed for each zone with the updated total enthalpy flow rate, total elemental mass flow rates, and elemental mass flow rates of the unburned char. The new temperature for each zone is obtained and under-relaxed. The new gas composition for each zone is also obtained from the equilibrium calculation and then used to update the gas emissivity and gas absorption coefficient. The convective heat transfer coefficient in each zone is then updated. With the updated zone temperatures, radiative properties and convective wall boundary conditions, the discrete radiative transfer equation is solved again on the 3-D mesh and this concludes the steps of one major iteration. The zone temperatures are compared with the old values obtained in the previous iteration. If the maximum difference between them is less than a user defined tolerance (usually set to $0.01 \mathrm{~K}$ ), the model is considered converged and the program exits the iteration loop. Finally, the modeling results are written, including two Paraview files for 3-D visualization if needed. 


\section{Application of Boiler Model}

The hybrid boiler model has been utilized to model two oxy-combustion systems found in the literature including a $1325 \mathrm{MW}_{\text {th }}$ utility boiler and a $0.5 \mathrm{MW}_{\text {th }}$ oxy-combustion test furnace. The modeling results are compared with measured data as well as CFD model results to validate the hybrid boiler model. Details of the two combustion systems including input data and modeling results are presented here.

\subsection{PacifiCorp Hunter Unit 3}

PacifiCorp's Hunter Unit 3 boiler was used as an example for validating the boiler model. Preliminary results have been previously reported (Ma et al., 2014). It is a utility boiler with a thermal power input of $1325 \mathrm{MW}$. Boiler geometry, operating conditions, and CFD modeling results were reported by Adams et al. (2013) of Reaction Engineering International (REI) in the technical report for a research project known as "Characterization of oxy-combustion impacts in existing coal-fired boilers," sponsored by National Energy Technology Laboratory (NETL). Both air-fired and oxy-fired cases were modeled such that the modeling results can be compared to those of the CFD cases reported by Adams et al.

\subsubsection{Hunter Unit 3 Model Setup}

Hunter Unit 3 is located in Castledale, Utah at an elevation of $1500 \mathrm{~m}$. It is a wall fired subcritical unit with $40 \mathrm{~B} \& \mathrm{~W}$ HV-4Z low-NOx burners, 10 overfire air (OFA) ports, and a platen finishing superheater inside the radiant furnace. The fuel used for Hunter Unit 3 is Utah Skyline bituminous coal. The fuel analysis data are tabulated in Table 3. Eleven size ranges, as listed in Table 4, were used to model the particle size distribution of the fuel.

Table 3. Fuel analysis data for Utah Skyline bituminous coal used by Hunter Unit 3

\begin{tabular}{|c|c|}
\hline Mass \% of C & 64.49 \\
\hline Mass \% of $\mathrm{H}$ & 4.44 \\
\hline Mass \% of O & 9.25 \\
\hline Mass \% of N & 1.18 \\
\hline Mass \% of S & 0.64 \\
\hline Mass \% of Moisture & 8.86 \\
\hline Mass \% of Ash & 11.14 \\
\hline Mass \% of Volatiles & 40.0 \\
\hline High Heating Value (kJ/kg) & 26360 \\
\hline
\end{tabular}

Table 4. Particle size distribution of Hunter Unit 3

\begin{tabular}{|c|c|c|}
\hline Size Range Number & Particle Diameter $(\mu \mathrm{m})$ & Mass Fraction \\
\hline 1 & 9.1 & 0.025 \\
\hline 2 & 16.3 & 0.05 \\
\hline 3 & 22.1 & 0.075 \\
\hline 4 & 28.6 & 0.1 \\
\hline
\end{tabular}




\begin{tabular}{|c|c|c|}
\hline 5 & 37.1 & 0.15 \\
\hline 6 & 50.2 & 0.2 \\
\hline 7 & 68.8 & 0.15 \\
\hline 8 & 89.8 & 0.1 \\
\hline 9 & 116 & 0.075 \\
\hline 10 & 155 & 0.05 \\
\hline 11 & 230 & 0.025 \\
\hline
\end{tabular}

Parameters related to the heterogeneous char reactions used in the model are listed in Table 5. The char oxidation data are based on the kinetic data for a bituminous coal reported by Hurt and Mitchell (1992) and the char gasification data are similar to those used by Adams et al. (2013). The furnace geometry data are listed in Table 6. The $X$ coordinate is in the depth direction with origin at the front wall, the $\mathrm{Y}$ coordinate is in the height direction with origin at the bottom of the hopper, and the $\mathrm{Z}$ coordinate is in the width direction with origin at the left side wall. The 3-D mesh and the 1-D zones of the model are shown in Figure 2. Ten zones along the boiler height are used for the models. The locations of the burners and the overfire ports are also displayed. The 3-D mesh for the radiative heat transfer calculation contains $26 \times 40 \times 24=24,960$ cells.

Table 5. Char reaction kinetic data used for Utah Skyline bituminous coal

\begin{tabular}{|c|c|c|}
\hline Parameter & Unit & Value \\
\hline Burning Mode Parameter $(\alpha$ in Eqn. 40) & None & 0.1 \\
\hline Activation Energy for $\mathrm{CO}_{2} / \mathrm{CO}$ Ratio & $\mathrm{J} / \mathrm{kmol}$ & $1.25 \times 10^{8}$ \\
\hline Pre-exponential Factor for $\mathrm{CO}_{2} / \mathrm{CO}$ Ratio & None & $4.0 \times 10^{4}$ \\
\hline Activation Energy for Char Oxidation by $\mathrm{O}_{2}$ & $\mathrm{~J} / \mathrm{kmol}^{2}$ & $1.0 \times 10^{8}$ \\
\hline Pre-Exponential Factor for Char Oxidation by $\mathrm{O}_{2}$ & $\mathrm{kmol} / \mathrm{kmol}^{0.5} \mathrm{~K}^{0.5} \mathrm{~m}^{0.5} \mathrm{~S}$ & 6.914 \\
\hline Activation Energy for Char Gasification by $\mathrm{H}_{2} \mathrm{O}$ & $\mathrm{J} / \mathrm{kmol}^{-}$ & $2.4 \times 10^{8}$ \\
\hline Pre-Exponential Factor for Char Gasification by $\mathrm{H}_{2} \mathrm{O}$ & $\mathrm{s}^{-1}$ & 208 \\
\hline Activation Energy for Char Gasification by $\mathrm{CO}_{2}$ & $\mathrm{~J} / \mathrm{kmol}^{-}$ & $2.51 \times 10^{8}$ \\
\hline Pre-Exponential Factor for Char Gasification by $\mathrm{CO}_{2}$ & $\mathrm{~s}^{-1}$ & 440 \\
\hline
\end{tabular}

Table 6. Geometry related input data for Hunter Unit 3

\begin{tabular}{|c|c|c|}
\hline Description & Unit & Value \\
\hline Number of Burner Levels & & 4 \\
\hline Number of Overfire Levels $^{\text {Number of Superheater Panels }}{ }^{\text {a }}$ & & 1 \\
\hline Number of Vertices of Superheater Polygon $^{\text {Furnace Depth (X) }}$ & & 11 \\
\hline Furnace Height (Y) & $\mathrm{m}$ & 4 \\
\hline
\end{tabular}




\begin{tabular}{|c|c|c|}
\hline Furnace Width $(\mathrm{Z})$ & $\mathrm{m}$ & 15.8496 \\
\hline X of Hopper Bottom of Front Wall & $\mathrm{m}$ & 6.7056 \\
\hline X of Hopper Bottom of Rear Wall & $\mathrm{m}$ & 8.8392 \\
\hline X of Nose Tip ${ }^{b}$ & $\mathrm{~m}$ & 10.668 \\
\hline Y of Hopper Knuckle & $\mathrm{m}$ & 9.144 \\
\hline Y of the Bottom of Nose Slope & $\mathrm{m}$ & 33.6804 \\
\hline Y of the Nose Tip & $\mathrm{m}$ & 36.8237 \\
\hline$X$ of Superheater Vertex $1^{b}$ & $\mathrm{~m}$ & 3.048 \\
\hline$X$ of Superheater Vertex $2^{b}$ & $\mathrm{~m}$ & 9.144 \\
\hline$X$ of Superheater Vertex $3^{b}$ & $\mathrm{~m}$ & 9.144 \\
\hline X of Superheater Vertex $4^{b}$ & $\mathrm{~m}$ & 3.048 \\
\hline Y of Superheater Vertex $1^{b}$ & $\mathrm{~m}$ & 38.7096 \\
\hline Y of Superheater Vertex $2^{b}$ & $\mathrm{~m}$ & 38.7096 \\
\hline Y of Superheater Vertex $3^{b}$ & $\mathrm{~m}$ & 51.816 \\
\hline Y of Superheater Vertex $4^{b}$ & $\mathrm{~m}$ & 51.816 \\
\hline Y of Burner Level 1 & $\mathrm{~m}$ & 12.192 \\
\hline Y of Burner Level 2 & $\mathrm{~m}$ & 14.9352 \\
\hline Y of Burner Level 3 & $\mathrm{~m}$ & 19.2024 \\
\hline Y of Burner Level 4 & $\mathrm{~m}$ & 21.9456 \\
\hline Y of Overfire Port Level 1 & $\mathrm{~m}$ & 25.1206 \\
\hline
\end{tabular}

a. Based on a figure in REI's report

b. Scaled based on a figure in REI's report

An air-fired case and an oxy-fired case modeled by REI were selected for the simulations using the hybrid boiler model. The operating conditions of the two cases are listed in Table 7. For the oxy-fired case, the $\mathrm{O}_{2}$ mole fraction in the secondary stream of the oxy-fired case is 0.26 (mass fraction of 0.23 ), corresponding to $75 \%$ flue gas recycle ratio. The same wall boundary conditions are used for the two cases. The emissivity of the enclosure water wall (with certain ash deposit) is 0.41 and the emissivity for the platen superheater wall (with limited ash deposit) is 0.7 . Note that wall emissivity is usually related to the ash composition of the coal fired and slagging condition inside a boiler. The wall emissivity is typically around 0.6 for boilers firing high-volatile bituminous coals and around 0.4 for those firing subbituminous coals. Wall emissivity of 0.41 used here in the boiler model is also the value that needs to be used in the CFD model to match the measured performance data of Hunter Unit 3 in air-fired conditions. The thermal resistances $\left(r_{\text {wall }}\right.$ in Eqn. 25) are 0.002 and $0.001 \mathrm{~m}^{2} \mathrm{~K} / \mathrm{W}$ for the enclosure water wall and the superheater wall, respectively. The fluid temperature ( $T_{\text {fluid }}$ in Eqn. 25$)$ is $623 \mathrm{~K}$ for the enclosure water wall (the saturation temperature at the drum pressure) and $700 \mathrm{~K}$ for the superheater wall (average steam temperature inside the superheater). The effectiveness factor of Eqn. 56 is set to 0.9 for all zones.

Table 7. Operating conditions of Hunter Unit 3 modeled

\begin{tabular}{|l|l|l|l|}
\hline & Unit & Air-Fired Case & Oxy-Fired Case \\
\hline
\end{tabular}




\begin{tabular}{|c|c|c|c|}
\hline Total Coal Flow Rate & $\mathrm{kg} / \mathrm{s}$ & 50.28 & 50.28 \\
\hline Total Air/O Flow Rate & $\mathrm{kg} / \mathrm{s}$ & 512.2104 & 102.44 \\
\hline Primary Stream Temperature & $\mathrm{K}$ & 338.71 & 355.37 \\
\hline Secondary Stream Temperature & $\mathrm{K}$ & 548.71 & 533.15 \\
\hline Coal Flow Rate Per Burner Level & $\mathrm{kg} / \mathrm{s}$ & 12.5714 & 12.5714 \\
\hline Primary Stream Flow Per Burner Level & $\mathrm{kg} / \mathrm{s}$ & 24.7658 & 22.6285 \\
\hline Secondary Stream Flow Per Burner Level & $\mathrm{kg} / \mathrm{s}$ & 72.8268 & 83.1027 \\
\hline Overfire Stream Flow Rate & $\mathrm{kg} / \mathrm{s}$ & 121.84 & 83.7886 \\
\hline Furnace Pressure & $\mathrm{Pa}$ & 86126 & 86126 \\
\hline
\end{tabular}

\subsubsection{Hunter Unit 3 Simulation Results}

A converged solution for a Hunter Unit 3 case can be reached after approximately 70 major iterations. The entire simulation takes approximately 60 seconds on a 64-bit laptop with a 2.2 GHz (Intel Core i7-4702) processor and 16 GB of RAM. A case is considered converged when the maximum difference in zone temperature between the current iteration and the previous iteration is less than $0.01 \mathrm{~K}$.

Table 8 lists the overall predictions by the hybrid boiler model for both air-fired and oxyfired cases along with the reported predictions of the CFD model. Note that the heat loss values for the CFD predictions were obtained by reading a bar chart in the REI's report. It can be seen from the table that the hybrid model predictions match quite well with the CFD model predictions. For the air-fired case, the hybrid boiler model predicts the temperature of the flue gas at the horizontal nose plane (leaving Zone 8 in the boiler model) at $1679 \mathrm{~K}, 5 \mathrm{~K}$ higher than the temperature predicted by the CFD model. The predicted unburned carbon in fly ash is $1.65 \%$, slightly lower than the CFD model prediction of $1.70 \%$. The predicted heat loss to the enclosure wall is $1.1 \%$ higher than the CFD model prediction and that to the superheater wall is $3.6 \%$ higher. The heat loss to all walls due to convection is $1.54 \times 10^{7} \mathrm{~W}$, accounting for $2.7 \%$ of total heat loss, which is reasonable for a large-scale utility boiler. Note that the heat loss due to convection was not reported for the CFD models by Adams et al. (2013). For the oxy-fired case, the hybrid boiler model predicts the temperature of the flue gas at the horizontal nose plane at $1649 \mathrm{~K}, 7 \mathrm{~K}$ lower than the temperature predicted by the CFD model. It predicts an unburned carbon in fly ash of $0.98 \%$, also slightly lower than the $1.10 \%$ predicted by the CFD model. The predicted heat losses to the enclosure and superheater walls are respectively $1.3 \%$ and $2.7 \%$ higher than the CFD model predictions. The heat loss to all walls due to convection is essentially the same as that of the air-fired case at $1.54 \times 10^{7} \mathrm{~W}$, accounting for $2.8 \%$ of total heat loss. Notice that both hybrid and CFD models predict the same trends in flue gas temperature, unburned carbon in fly ash, and heat losses to boiler walls when firing configuration is changed from air-fired to oxy-fired. The oxy-fired case has a lower flue gas temperature at the horizontal nose plane, a lower unburned carbon in fly ash, a lower heat loss to the enclosure wall, and a higher heat loss to the platen superheater than the air-fired case. 
Table 8. Overall model predictions of Hunter Unit 3 cases

\begin{tabular}{|c|c|c|c|c|c|}
\hline & & \multicolumn{2}{|c|}{ Air-Fired } & \multicolumn{2}{c|}{ Oxy-Fired } \\
\hline & Unit & Boiler Model & CFD Model & Boiler Model & CFD Model \\
\hline $\begin{array}{c}\text { Flue Gas Temperature at } \\
\text { Horizontal Nose Plane }\end{array}$ & $\mathrm{K}$ & 1679 & 1674 & 1649 & 1656 \\
\hline Unburned Carbon in Fly Ash & $\mathrm{wt} \%$ & $1.65 \%$ & $1.70 \%$ & $0.98 \%$ & $1.10 \%$ \\
\hline Heat Loss to Enclosure Wall & $\mathrm{W}$ & $4.41 \times 10^{8}$ & $4.36 \times 10^{8} \mathrm{a}$ & $4.12 \times 10^{8}$ & $4.07 \times 10^{8 \mathrm{a}}$ \\
\hline Heat Loss to Platen Superheater & $\mathrm{W}$ & $1.02 \times 10^{8}$ & $9.85 \times 10^{7} \mathrm{a}$ & $1.15 \times 10^{8}$ & $1.12 \times 10^{8 \mathrm{a}}$ \\
\hline Total Convective Heat Loss & $\mathrm{W}$ & $1.54 \times 10^{7}$ & & $1.54 \times 10^{7}$ & \\
\hline
\end{tabular}

a. Read from a figure in REI's report

To understand the result of the lower unburned carbon in fly ash predicted for the oxyfired case, flue gas flow rate, flue gas composition and molecular weight at model exit, residence times and char reaction rates by the three gas reactants $\left(\mathrm{O}_{2}, \mathrm{H}_{2} \mathrm{O}\right.$, and $\left.\mathrm{CO}_{2}\right)$ are examined as shown in Table 9. The total zone residence time listed in the table is the sum of the residence times of all zones except the hopper zone. The average coal particle residence time is the average value for particles fed to 4 burner levels from Zone 2 to Zone 5. While the total flue gas flow rate of the two cases are similar, the coal particle residence time in the oxy-fired case is higher due to the higher molecular weight of the gas mixture and hence higher gas densities and lower gas velocities inside the boiler. A longer particle residence time results in a higher carbon conversion and, therefore, a lower unburned carbon in fly ash if the reaction temperature and reactant concentrations are the same. The zone temperatures are lower in the oxy-fired case (see Table 8 and the discussion later), which results in lower reaction rates. The mole fractions of the three gas reactants are different with $\mathrm{O}_{2}$ mole fraction lower and $\mathrm{CO}_{2}$ and $\mathrm{H}_{2} \mathrm{O}$ mole fractions much higher in the oxy-fired case. The overall effects of the three factors mentioned above cause a total reaction rate slightly higher, resulting in a lower carbon in fly ash. Among the three heterogeneous reactions, the char oxidation rate is lower in the oxy-fired case but the char gasification rates by $\mathrm{H}_{2} \mathrm{O}$ and $\mathrm{CO}_{2}$ are significantly higher due to the high concentrations of the two reactants.

Table 9. Additional results predicted by hybrid boiler model of Hunter Unit 3 cases

\begin{tabular}{|c|c|c|c|}
\hline & Unit & Air-Fired & Oxy-Fired \\
\hline Flue Gas Mass Flow Rate & $\mathrm{kg} / \mathrm{s}$ & 555.1 & 551.3 \\
\hline Mole Fraction of $\mathrm{O}_{2}$ In Flue Gas & & 0.0298 & 0.0230 \\
\hline Mole Fraction of $\mathrm{N}_{2}$ In Flue Gas & & 0.7389 & 0.0058 \\
\hline Mole Fraction of $\mathrm{H}_{2} \mathrm{O}$ In Flue Gas & & 0.0869 & 0.2299 \\
\hline Mole Fraction of $\mathrm{CO}_{2}$ In Flue Gas & & 0.1439 & 0.7386 \\
\hline Mole Fraction of $\mathrm{SO}_{2}$ In Flue Gas & & 0.0005 & 0.0027 \\
\hline Molecular Weight of Flue Gas & $\mathrm{kg} / \mathrm{kmol}$ & 29.6 & 37.7 \\
\hline Total Zone Residence Time & $\mathrm{s}$ & 4.39 & 5.50 \\
\hline
\end{tabular}




\begin{tabular}{|c|c|c|c|}
\hline Average Coal Particle Residence Time & $\mathrm{s}$ & 2.29 & 2.91 \\
\hline Rate of Char Oxidation by $\mathrm{O}_{2}$ & $\mathrm{~kg} / \mathrm{s}$ & 18.00 & 15.67 \\
\hline Rate of Char Gasification by $\mathrm{H}_{2} \mathrm{O}$ & $\mathrm{kg} / \mathrm{s}$ & 0.75 & 1.03 \\
\hline Rate of Char Gasification by $\mathrm{CO}_{2}$ & $\mathrm{~kg} / \mathrm{s}$ & 1.28 & 3.36 \\
\hline Total Heterogeneous Char Reaction Rate & $\mathrm{kg} / \mathrm{s}$ & 20.02 & 20.06 \\
\hline
\end{tabular}

Figure 6 shows the temperatures in individual zones for the two cases. The oxy-fired case has lower temperatures in the individual zones. Figure 7 shows the gas emissivities for the 10 zones. As expected, much higher gas emissivities are predicted for the oxy-fired case due to the higher concentrations of $\mathrm{CO}_{2}$ and $\mathrm{H}_{2} \mathrm{O}$. As mentioned in REI's report, the $75 \%$ flue gas recycle ratio in the oxy-fired case is approximately the optimal ratio for matching the heat releases to the enclosure water wall and the superheater wall in the air-fired case. It is reasonable to predict lower zone temperatures in the oxy-fired case than in the air-fired case as shown in Figure 6, since the gas emissivities in the oxy-fired case are much higher than those in the airfired case as shown in Figure 7. Figure 8 shows the inner wall temperatures (temperatures of ash deposit) at the boundary faces of the 3-D mesh. Overall, the predicted wall temperature distributions in the both cases are very similar. Notice that the wall temperatures at the water wall near the platen superheater are much lower due to the blockage of radiation from the coal flame by the nearby superheater panels. Also notice that the temperatures at four corner regions are lower even though uniform gas temperatures are assigned to all cells in each zone. The 3-D effect on the radiative transfer is captured in the hybrid boiler model. Figure 9 shows the net radiation heat flux at the model boundaries. The right side wall is removed to show the heat flux at the superheater wall. The oxy-fired case has slightly lower net radiation heat fluxes in the lower furnace mainly due to the lower zone temperatures even though its gas emissivities are higher. However, in the upper furnace, especially at the superheater wall, the net radiation heat fluxes are slightly higher. This trend is consistent with the lower heat loss to the enclosure wall and the higher heat loss to the platen superheater as listed in Table 8.

Good agreement between the hybrid boiler model predictions and the CFD model predictions for the two cases modeled is achieved when reasonable input data related to the reaction kinetics, the effectiveness factor $f_{\text {mixedness }}$, and wall boundary condition (e.g. overall heat transfer resistance $r_{w}$ and wall emissivity $\epsilon_{w}$ ) are applied. These inputs have physical meaning as with any first-principles model. In the boiler model, the effectiveness factor $f_{\text {mixedness }}$ is related to the deviation from the well-mixed reactor assumption, the overall heat transfer resistance $r_{w}$ is related to the slagging potential of the coal ash, and wall emissivity $\epsilon_{w}$ is related to the radiation property of ash deposit (Reflective coal ash found in lower rank coals tends to have a lower emissivity). As with all first-principles models, accurate model inputs are essential for accurate model predictions. Guidelines for choosing correct inputs could be learned through comparison of predictions and real performance data, but are difficult to obtain for largescale oxy-fired boiler configurations. 


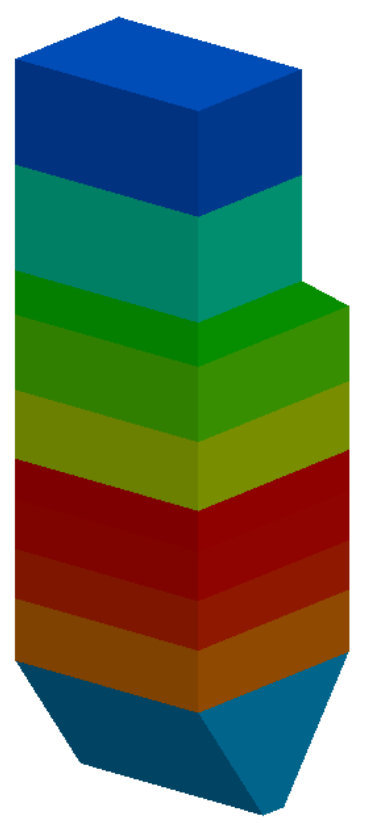

(a) Air-fired Case

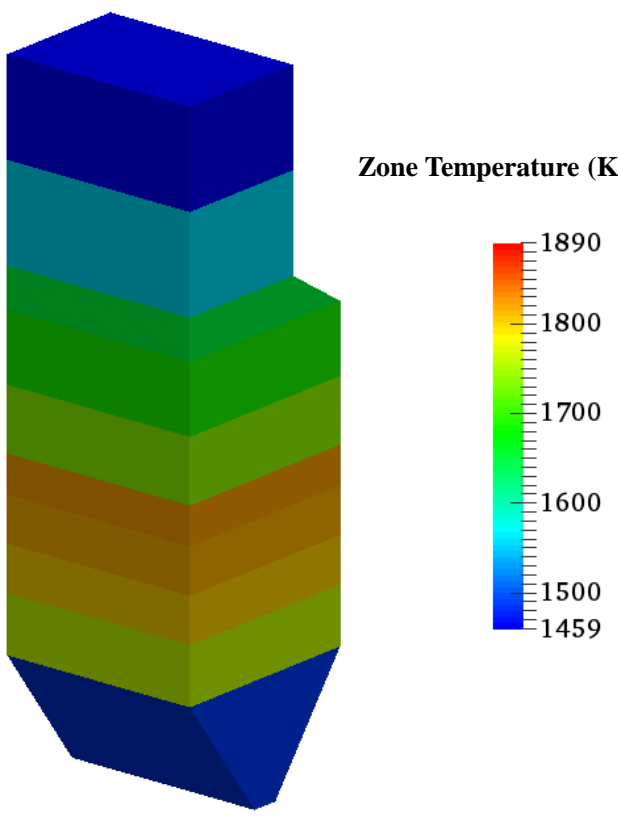

(b) Oxy-fired Case

Figure 6. Predicted zone temperatures for Hunter Unit 3

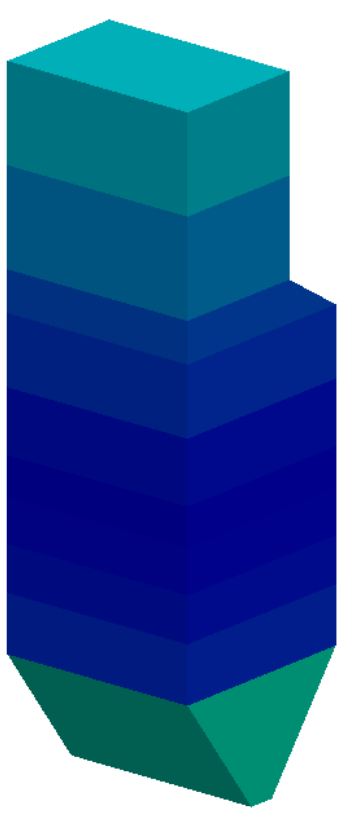

(a) Air-fired Case

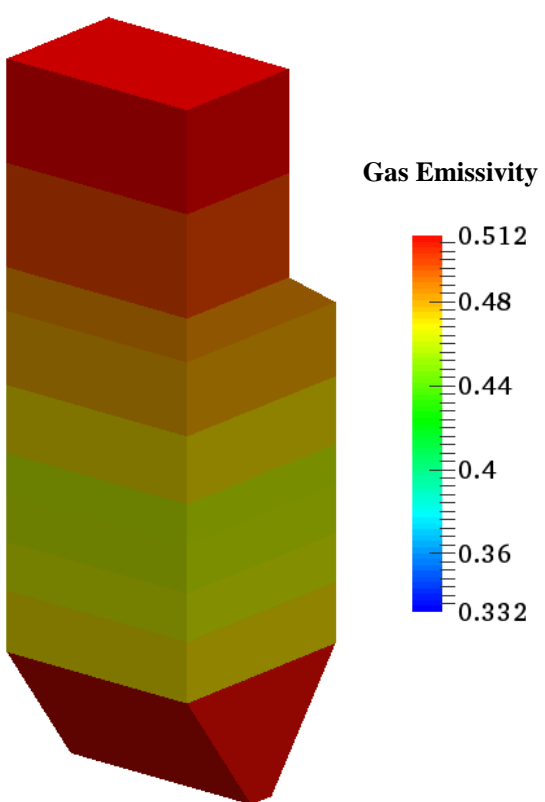

(b) Oxy-fired Case

Figure 7. Predicted zone gas emissivity for Hunter Unit 3 


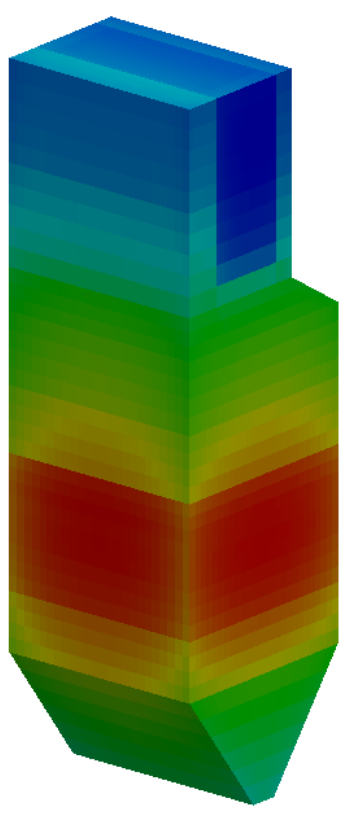

(a) Air-fired Case

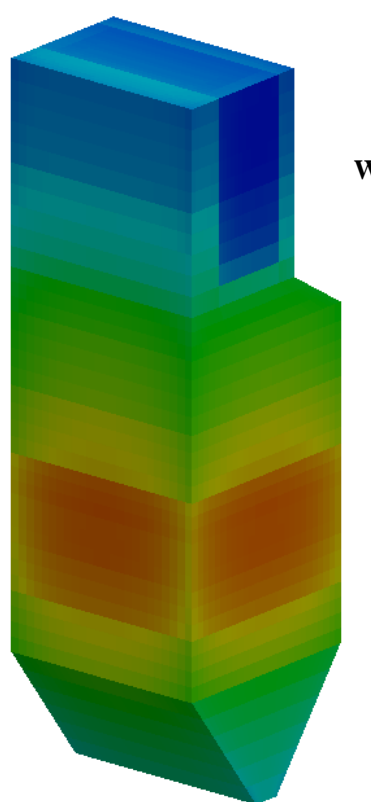

(b) Oxy-fired Case
Wall Temperature $(\mathbf{K})$

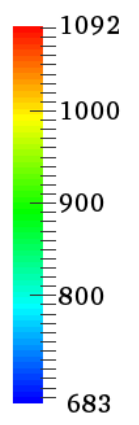

Figure 8. Predicted inner wall temperatures on the 3-D mesh for Hunter Unit 3

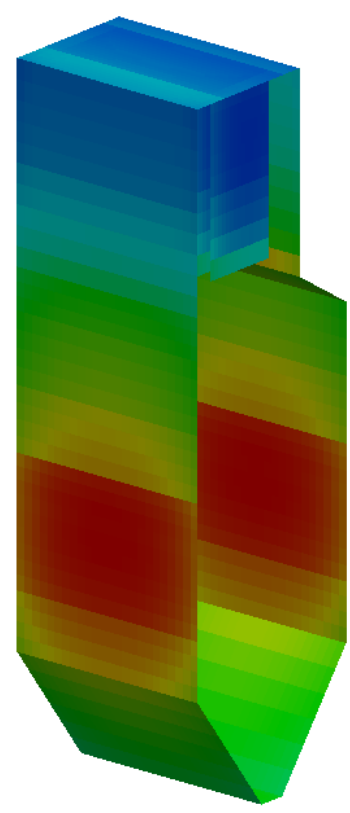

(a) Air-fired Case

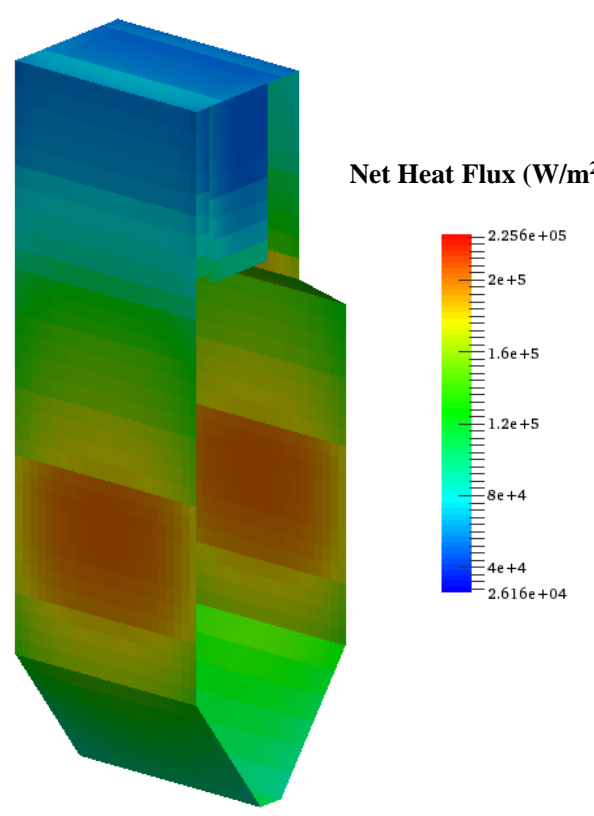

(b) Oxy-fired Case

Figure 9. Predicted net radiation heat flux on the 3-D mesh for Hunter Unit 3

The effects of zone and mesh resolutions on boiler model predictions were also studied. Like a typical CFD model, computational mesh needs to be fine enough such that it has 
minimum effects on model predictions. The air-fired case of Hunter Unit 3 model reported above was used as the baseline case. Then the number of 1-D zones from the hopper knuckle to the bottom of the nose was increased from 6 in the baseline model shown in Figure 2 to 12, the number of zones in the nose region was increased from 1 to 2 , and the total number of 3-D cells was increased from 24,960 to 39,936 . The predicted FEGT increased by $0.3 \mathrm{~K}$ and the predicted unburned carbon in fly ash decreased from $1.65 \%$ to $1.32 \%$. This means the resolution of 1-D zone has negligible effect on the predicted flue gas temperature at the model exit but has certain effect on the predicted unburned carbon in fly ash. When the number of 1-D zones was kept unchanged at 10 as in the baseline case and the number of 3-D cells in each direction was doubled, i.e., the total number of 3-D cells was eight times that of the baseline case, the predicted flue gas temperature at the horizontal nose plane increased by only $0.05 \mathrm{~K}$ and the predicted carbon in fly ash decreased from $1.650 \%$ to $1.647 \%$. This means the $3-\mathrm{D}$ mesh size in the baseline model is fine enough. Care must be taken when discretizing boiler geometry to multiple 1-D zones. It is recommend that there be at least one zone to cover one burner or overfire level. There is always a trade-off between model accuracy and required CPU time.

\subsection{5 MW $\mathrm{MW}_{\text {th }}$ Oxy-Combustion Test Furnace}

Measurements of radiative heat transfer, unburned carbon and other experimental data were reported based on a series of oxy-combustion experiments carried out in a $0.5 \mathrm{MW}_{\text {th }}$ Combustion Test Facility (CTF) at RWE npower (Smart et al., 2010b). The CTF has a refractory lined, water jacketed combustion chamber of approximately $4 \mathrm{~m}$ long with an inner cross-section of $0.8 \mathrm{~m}$ by $0.8 \mathrm{~m}$ followed by a refractory lined (no water jacket) truncated pyramid section of $2.18 \mathrm{~m}$ long with an inner cross section at the end of $0.3 \mathrm{~m}$ by $0.3 \mathrm{~m}$. A pulverized coal burner is installed at the front of the horizontal furnace. Figure 10 shows the geometry of the CTF (Smart et al., 2010b). Both air-fired and oxy-fired experiments have been conducted using a Russian coal as the fuel. In the oxy-fired experiments, gas mixtures of $\mathrm{CO}_{2}$ and $\mathrm{O}_{2}$ were used as primary and secondary streams to mimic dry flue gas recycle. A few researchers have modeled a handful of selected test cases using commercial CFD software with certain user customization (Hu and Yan, 2013; Rebola and Azevedo, 2015). Even though the local burner effect in a small combustion chamber may lead to deviations from some assumptions in Section 2.2, four test cases including one baseline air-fired case and three oxy-fired cases were chosen to explore the applicability of the hybrid boiler model to the CTF experiments. The incident radiation heat flux measurements along the length of the furnace provide valuable model validation data. 


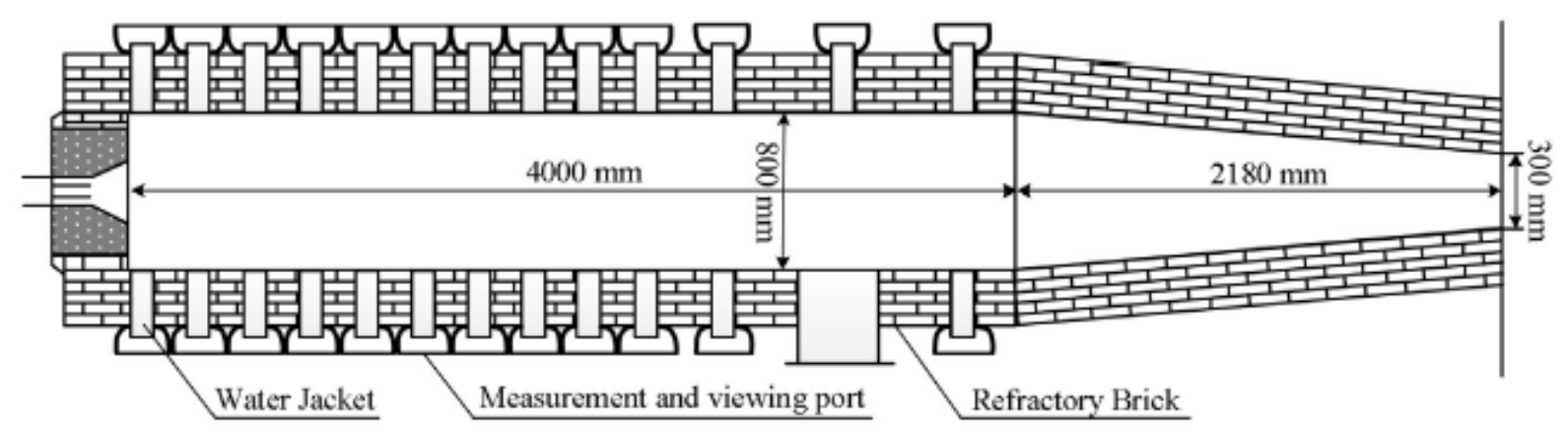

Figure 10. Schematic of RWE npower's Combustion Test Facility

\subsubsection{RWE's CTF Model Setup}

Currently the hybrid boiler model assumes a constant boiler width. In the case of the CTF furnace, the main section of $4 \mathrm{~m}$ length is modeled correctly while the truncated pyramid section is converted to a trapezoidal prism with a base depth of $0.8 \mathrm{~m}$ and top depth of $0.3 \mathrm{~m}$ and a constant width of $0.8 \mathrm{~m}$. This slight modification of the geometry in the well-insulated second section (the truncated pyramid section) simplifies the model, and should have negligibly impact on model predictions, especially in the first section.

The fuel analysis data for the Russian coal used in the experiments are tabulated in Table 10. The size distribution of the fuel provided in the original paper (Smart et al., 2010b) was fitted to a log-normal distribution and discretized to 11 size ranges as listed in Table 11.

Table 10. Fuel analysis data for Russian coal used at CTF

\begin{tabular}{|c|c|}
\hline Mass \% of C & 65.91 \\
\hline Mass \% of H & 4.59 \\
\hline Mass \% of O & 8.89 \\
\hline Mass \% of N & 2.09 \\
\hline Mass \% of S & 0.34 \\
\hline Mass \% of Moisture & 6.23 \\
\hline Mass \% of Ash & 11.95 \\
\hline Mass \% of Volatiles & 33.55 \\
\hline High Heating Value $(\mathrm{kJ} / \mathrm{kg})$ & 27098 \\
\hline
\end{tabular}

Table 11. Particle size distribution of Russian coal used at CTF

\begin{tabular}{|c|c|c|}
\hline Size Range Number & Particle Diameter $(\mu \mathrm{m})$ & Mass Fraction \\
\hline 1 & 7.5 & 0.025 \\
\hline 2 & 13.5 & 0.05 \\
\hline 3 & 18.4 & 0.075 \\
\hline 4 & 23.7 & 0.1 \\
\hline
\end{tabular}




\begin{tabular}{|c|c|c|}
\hline 5 & 30.8 & 0.15 \\
\hline 6 & 41.8 & 0.2 \\
\hline 7 & 57.3 & 0.15 \\
\hline 8 & 74.9 & 0.1 \\
\hline 9 & 96.5 & 0.075 \\
\hline 10 & 129.3 & 0.05 \\
\hline 11 & 192.9 & 0.025 \\
\hline
\end{tabular}

Char kinetic data were adjusted slightly based on the bituminous coal used in the Hunter Unit 3 case such that unburned carbon predicted in the baseline air-fired case are close to the measured value. The activation energy for the char oxidation reaction was increased by $10 \%$ and the corresponding pre-exponential factor was decreased by 50\%. All other kinetic parameters were kept unchanged.

The 3-D mesh and the 1-D zones of the model are shown in Figure 11. Sixteen zones along the length of the test furnace are used in the model. Zones 1-10 have the water jacket and Zones 11-16 contain the refractory wall only. The 3-D mesh for the radiative heat transfer calculation contains $20 \times 62 \times 20=24800$ cells.
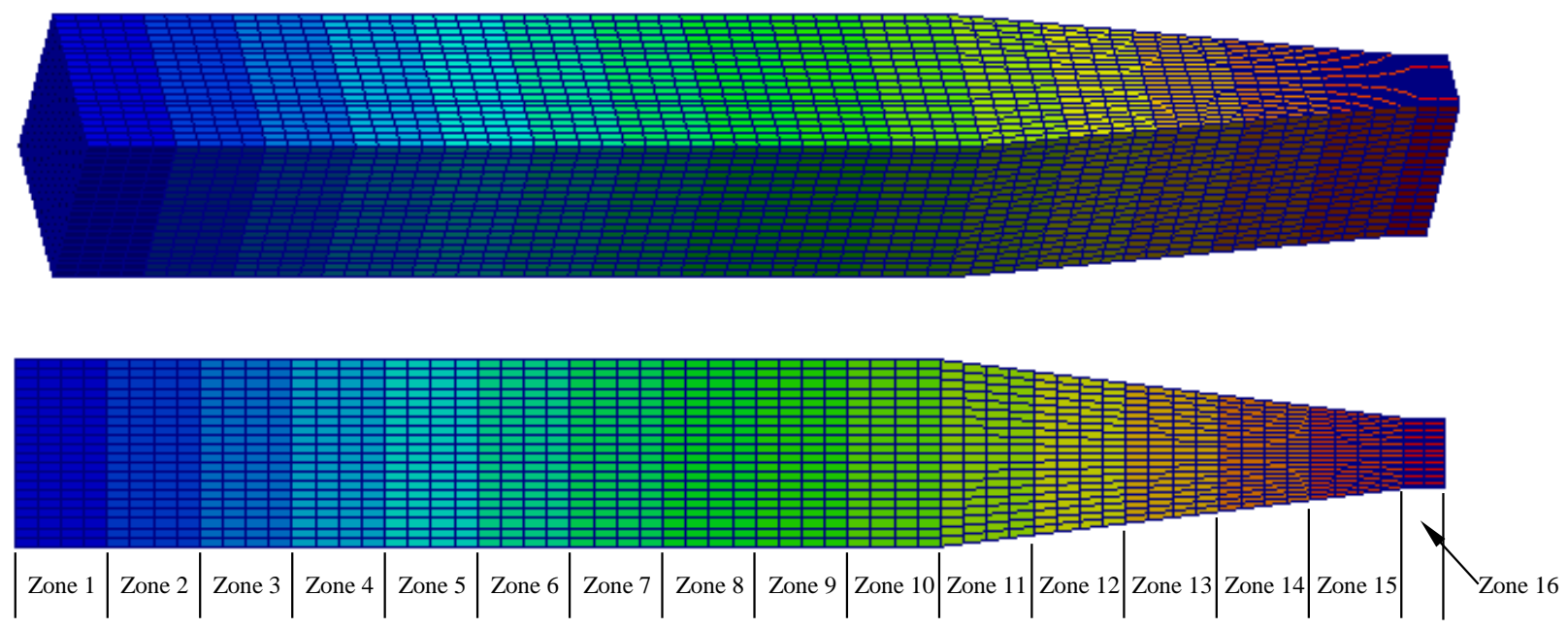

Figure 11. Discretized 3-D mesh and 1-D zones for RWE's CTF model

The operating conditions of the four cases modeled are listed in Table 12. The actual flow rates of the primary and secondary streams were not reported in the paper by Smart et al. (2010b). Instead, the total flow rate (primary and secondary streams) for each case is calculated based on the reported overall effective $\mathrm{O}_{2}$ level (the average of $\mathrm{O}_{2}$ in the primary and secondary streams) and the reported $3 \mathrm{vol} \% \mathrm{O}_{2}$ level in the flue gas. The primary stream flow rate was assumed to be the same as the one reported in another paper by the same first author in the same 
year (Smart et al., 2010a). The secondary stream flow rate is calculated as the balance. The operating pressure of $1 \mathrm{~atm}(101325 \mathrm{~Pa})$ is assumed.

Table 12. Operating conditions of CTF cases modeled

\begin{tabular}{|c|c|c|c|c|c|}
\hline & Unit & Air-Fired & Oxy 1 & Oxy 2 & Oxy 3 \\
\hline Overall Effective $\mathrm{O}_{2}$ Level & vol\% & $21.0 \%$ & $36.0 \%$ & $29.0 \%$ & $26.5 \%$ \\
\hline Primary Stream $\mathrm{O}_{2}$ & $\mathrm{vol} \%$ & $21.0 \%$ & $21.0 \%$ & $21.0 \%$ & $21.0 \%$ \\
\hline Secondary Stream $\mathrm{O}_{2}$ & $\mathrm{vol} \%$ & $21.0 \%$ & $42.1 \%$ & $31.4 \%$ & $27.3 \%$ \\
\hline Total Coal Flow Rate & $\mathrm{kg} / \mathrm{s}$ & 0.04845 & 0.04845 & 0.04845 & 0.04845 \\
\hline Primary Stream Flow Rate & $\mathrm{kg} / \mathrm{s}$ & 0.03000 & 0.04306 & 0.04306 & 0.04306 \\
\hline Secondary Stream Flow Rate & $\mathrm{kg} / \mathrm{s}$ & 0.15968 & 0.09927 & 0.14141 & 0.16732 \\
\hline Primary Stream Temperature & $\mathrm{K}$ & 343.15 & 343.15 & 343.15 & 343.15 \\
\hline Secondary Stream Temperature & $\mathrm{K}$ & 543.15 & 543.15 & 543.15 & 543.15 \\
\hline Furnace Pressure & $\mathrm{Pa}$ & 101325 & 101325 & 101325 & 101325 \\
\hline Effectiveness Factor & & 0.6 & 0.3 & 0.6 & 0.9 \\
\hline
\end{tabular}

The same wall boundary conditions are used for all 4 cases. The emissivity of the refractory wall is 0.6. The thermal resistances $\left(r_{\text {wall }}\right.$ in Eqn. 25$)$ are $0.07 \mathrm{~m}^{2} \mathrm{~K} / \mathrm{W}$ for the first section (the water jacketed section) and $0.5 \mathrm{~m}^{2} \mathrm{~K} / \mathrm{W}$ for the second section (without the water jacket). The fluid temperature $\left(T_{\text {fluid }}\right.$ in Eqn. 25$)$ is $350 \mathrm{~K}$ for the both sections.

Since the CTF has only one burner at the front wall and the volume of the furnace is small, the local burner effect is strong; mixing between the primary and secondary streams in the first few zones is limited. Therefore, effectiveness factors need to be applied. The "mixedness" inside the test furnace is related to the strength of the turbulent swirling flow, i.e., the velocities and mass flow rates of primary and secondary streams. Among the three oxy-fired cases, Oxy Case 1 has the lowest total gas flow rate, and hence, the lowest effectiveness factor. Table 12 lists the effectiveness factors for the "mixedness" used in all zones. Note that the Oxy 2 case has a similar total gas flow rate to that of the air-fired case and the same effectiveness factor of 0.6 is applied to the two cases.

\subsubsection{RWE's CTF Simulation Results}

CPU time similar to the Hunter Unit 3 case is required to obtain a converged solution of the CTF model. The overall predictions including flue gas temperature at the model exit, total heat loss and convective heat loss to the boundary walls, and unburned carbon in fly ash are tabulated in Table 13. The measured data for unburned carbon in fly ash are also listed in Table 13. Although the exit gas temperature and the net radiation heat loss were not reported in the paper by Smart et al. (2010b), it is mentioned that Oxy 2 case with $29 \%$ effective $\mathrm{O}_{2}$ level corresponding to $72 \%$ recycle ratio is equivalent to the air-fired case. As shown in Table 13, the predicted total heat losses of the air-fired case and Oxy 2 case are very close and the difference 
in predicted gas temperature at the model exit is only $13 \mathrm{~K}$. Convective heat loss is negligible $(<0.2 \%$ of total heat loss $)$ compared to radiative heat loss due to very low gas velocities in the first section (average velocity $<2.5 \mathrm{~m} / \mathrm{s}$ ). Among the three oxy-fired cases, the case with the highest effective $\mathrm{O}_{2}$ level tends to have the highest heat loss and the highest exit gas temperature since the adiabatic flame temperature is the highest due to the minimum dilution by the recycled flue gas. With the adjustment of the effectiveness factor related to the "mixedness" of the fuel and the oxidant, the predicted unburned carbon data are in good agreement with the measured data. The air-fired case has higher unburned carbon in the fly ash than the oxy-fired cases.

Table 13. Overall model predictions of CTF cases

\begin{tabular}{|c|c|c|c|c|c|}
\hline & Unit & Air-Fired & Oxy 1 & Oxy 2 & Oxy 3 \\
\hline Gas Temperature at Model Exit & $\mathrm{K}$ & 1456 & 1531 & 1443 & 1402 \\
\hline Total Heat Loss & $\mathrm{kW}$ & 234.1 & 261.8 & 235.3 & 224.5 \\
\hline Convective Heat Loss & $\mathrm{kW}$ & 0.60 & 0.43 & 0.44 & 0.45 \\
\hline Unburned Carbon (Predicted) & $\mathrm{wt} \%$ & $3.26 \%$ & $0.72 \%$ & $1.32 \%$ & $1.47 \%$ \\
\hline Unburned Carbon (Measured) & $\mathrm{wt} \%$ & $2.1 \%$ & $0.5 \%$ & $0.9 \%$ & $0.5 \%$ \\
\hline
\end{tabular}

Figure 12 shows the predicted temperatures in the 16 zones for the four cases modeled. It can be seen that Oxy 1 has the highest zone temperatures, again due to the highest adiabatic flame temperature. Figure 13 shows the predicted gas emissivities in the 16 zones in the boiler model. Notice that the emissivities for the three oxy-fired cases are much higher than those for the air-fired cases due to the recycled flue gas. Figure 14 shows the corresponding wall temperatures on the 3-D mesh. Wall temperatures are quite uniform along the circumference at any axial location since the cross section is quite small compared with the furnace length. Figure 15 shows the incident radiation heat flux on the 3-D mesh of the test furnace. The average incident heat fluxes of individual zones for the four cases modeled are plotted in Figure 16 along with the measure incident heat flux data. Overall, the boiler model predicts values that are higher than the measured experimental data. However, the predicted trends of the heat flux profiles are very similar to those from the measured data. The discrepancy for the $36 \% \mathrm{O}_{2}$ case is quite large between the predicted and measured data. At a high effective $\mathrm{O}_{2}$ level, the small amount of change in secondary stream flow rate could result in a large change in the adiabatic flame temperature and an even larger change in the incident heat flux, since emission is proportional to the $4^{\text {th }}$ power of temperature. While modeling the small test furnace using the boiler model is challenging due to the limited consideration on local fluid dynamics and mixing effects, the uncertainties in the actual flow rates used in the experiments may also attribute to the discrepancy in the magnitude of the incident heat flux data. Nevertheless, the boiler model does predict correct trends of the flux profile along the axial length of the furnace.

Again, reasonable predictions are obtained when reasonable input data such as the effectiveness factor related to the zone "mixedness" are specified. Due to limited knowledge 
about the effectiveness factor without explicitly modeling turbulent mixing, the applicability of the boiler model to those small test furnaces is limited. More validation work by modeling a similar test furnace for oxy-combustion experiments with well documented experimental data are planned.

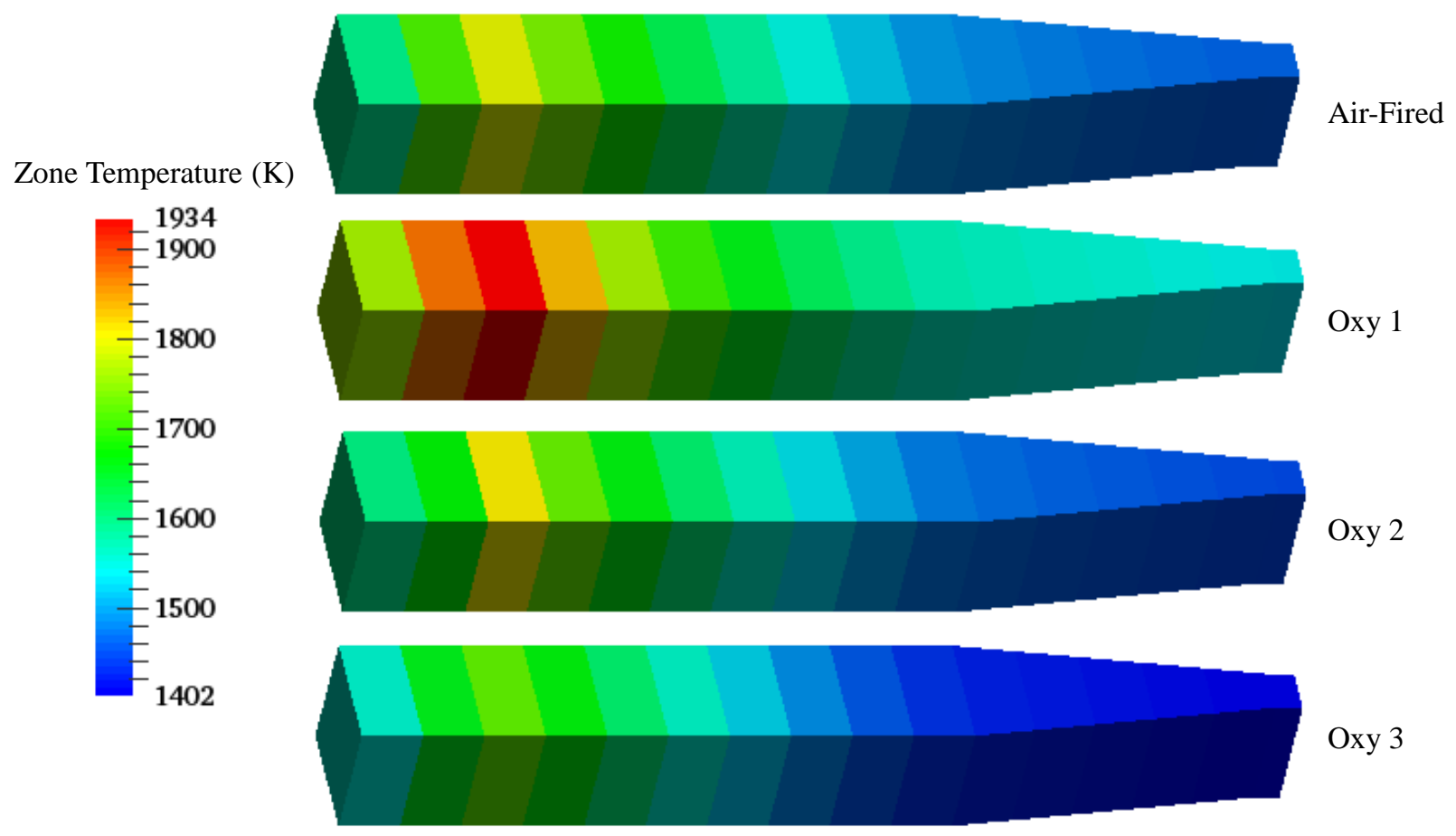

Figure 12. Predicted zone temperatures for CTF 


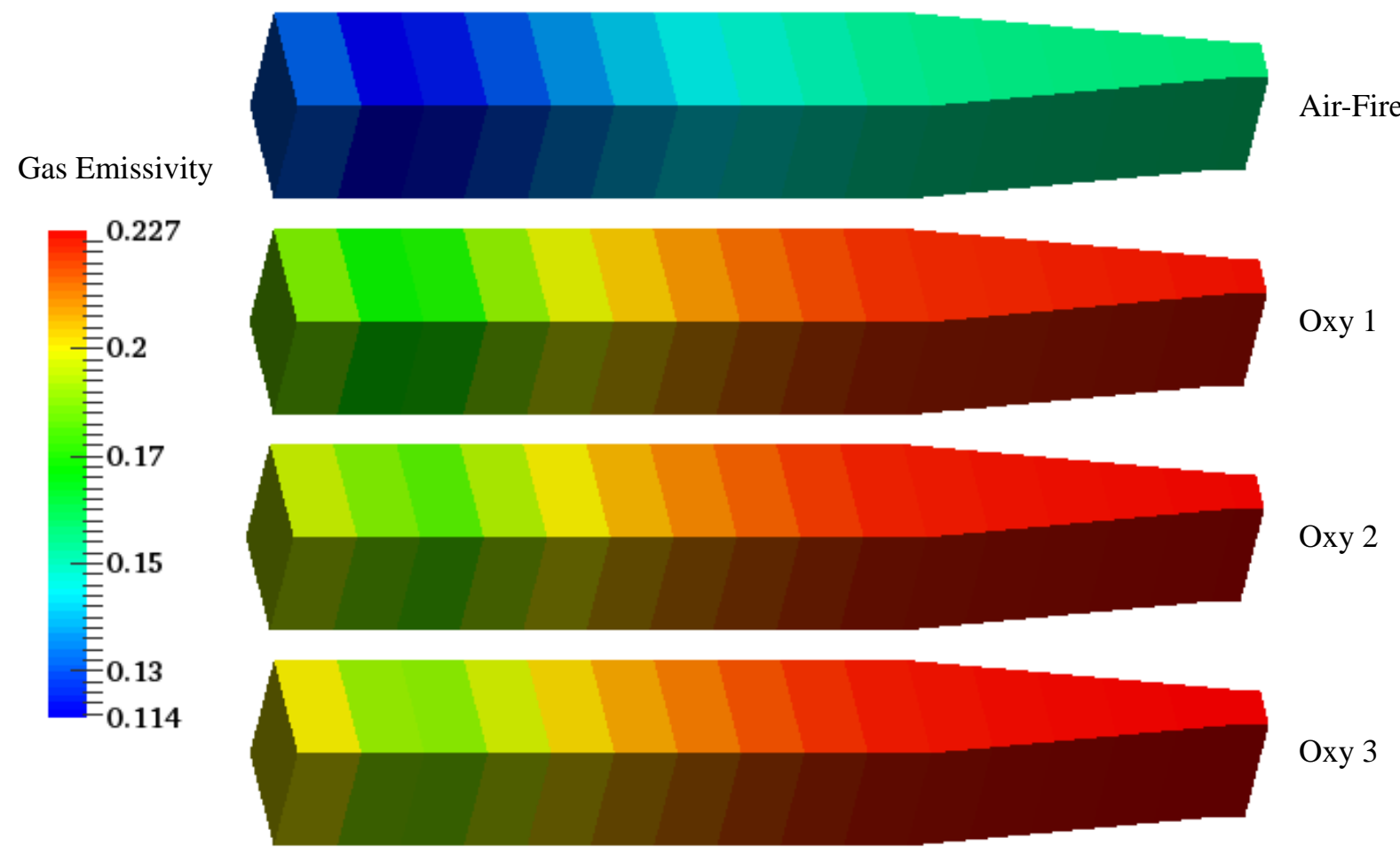

Figure 13. Predicted gas emissivity for CTF

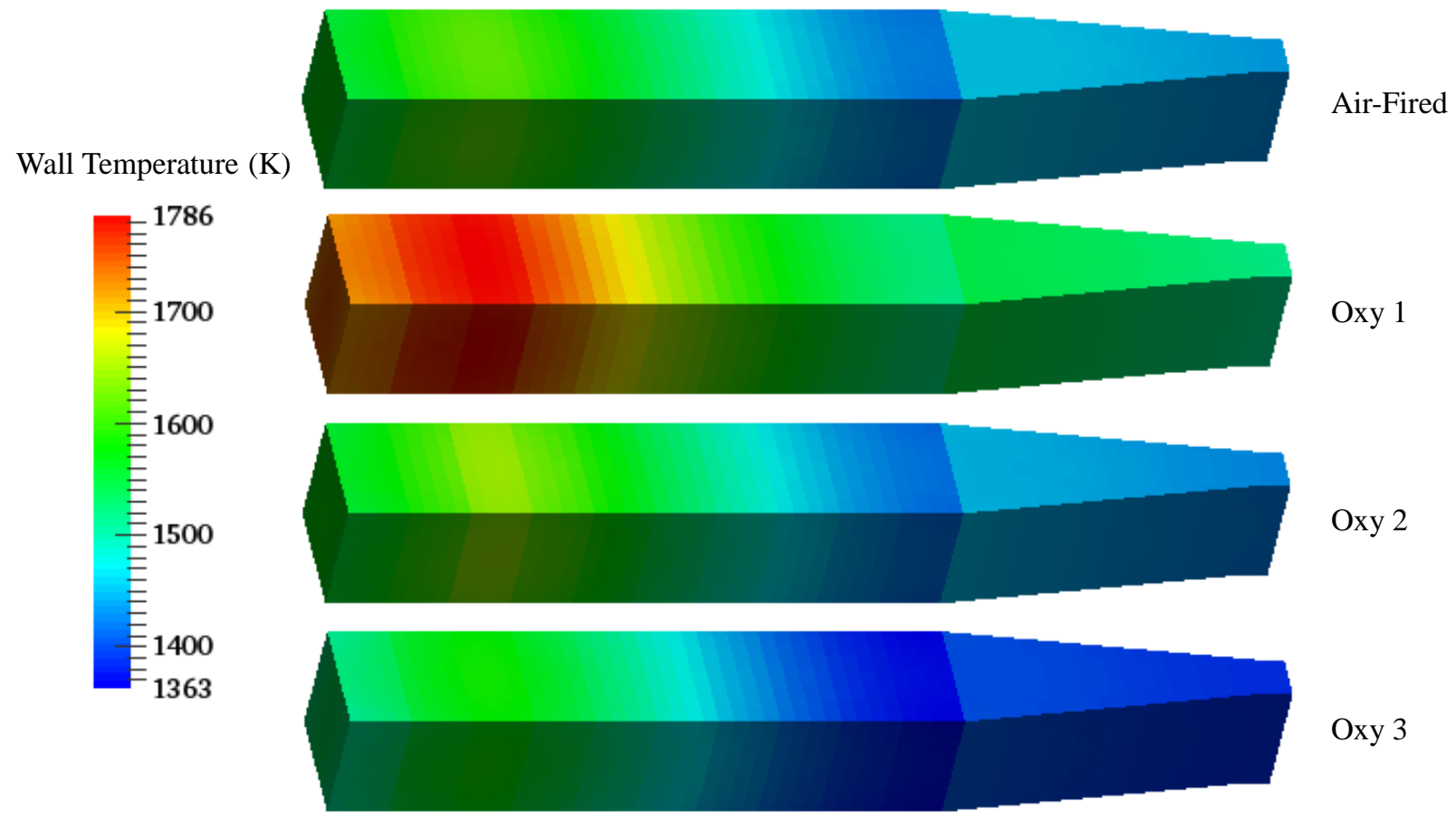

Figure 14. Predicted inner wall temperature for CTF 


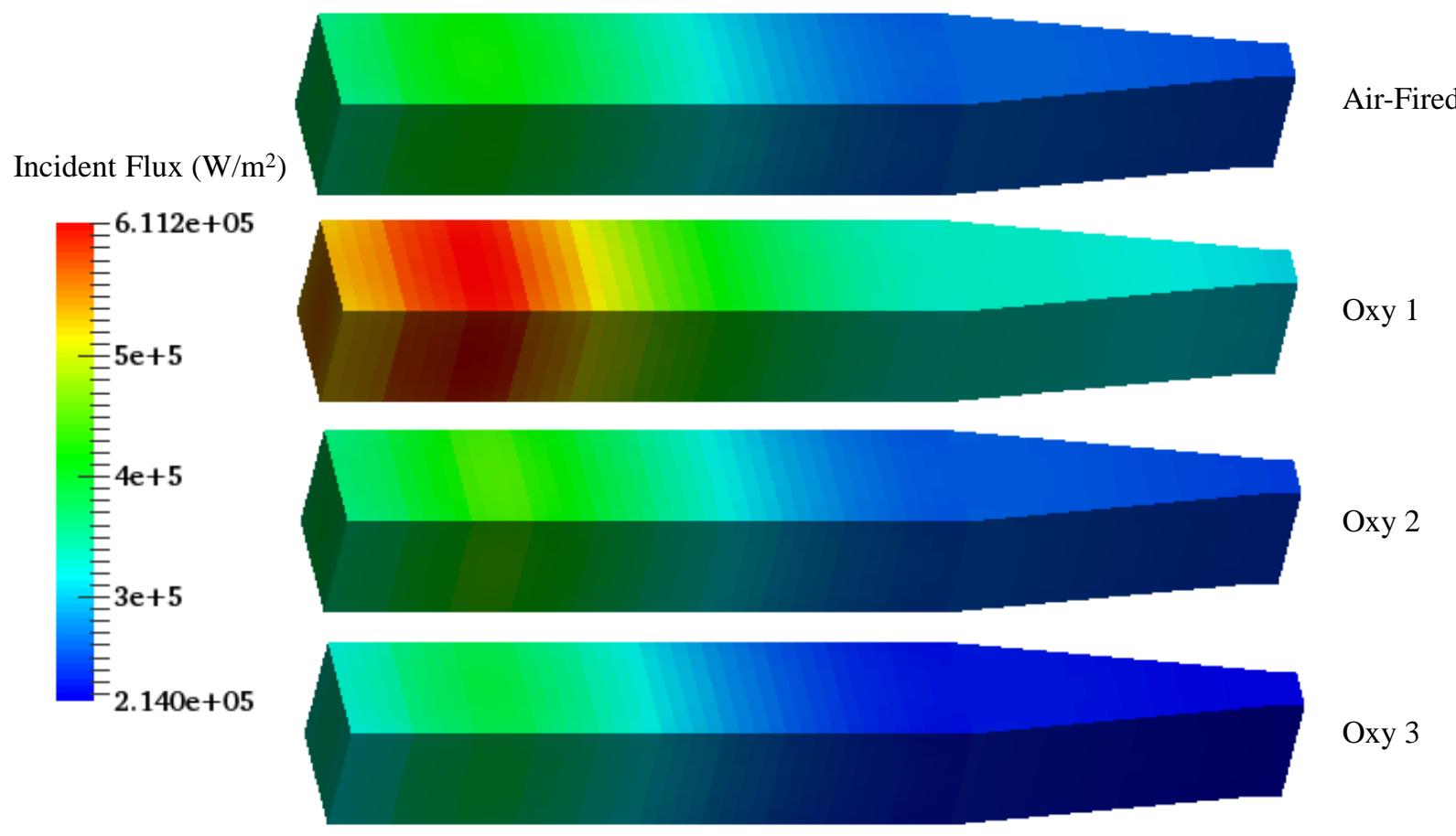

Figure 15. Predicted incident radiation heat flux for CTF

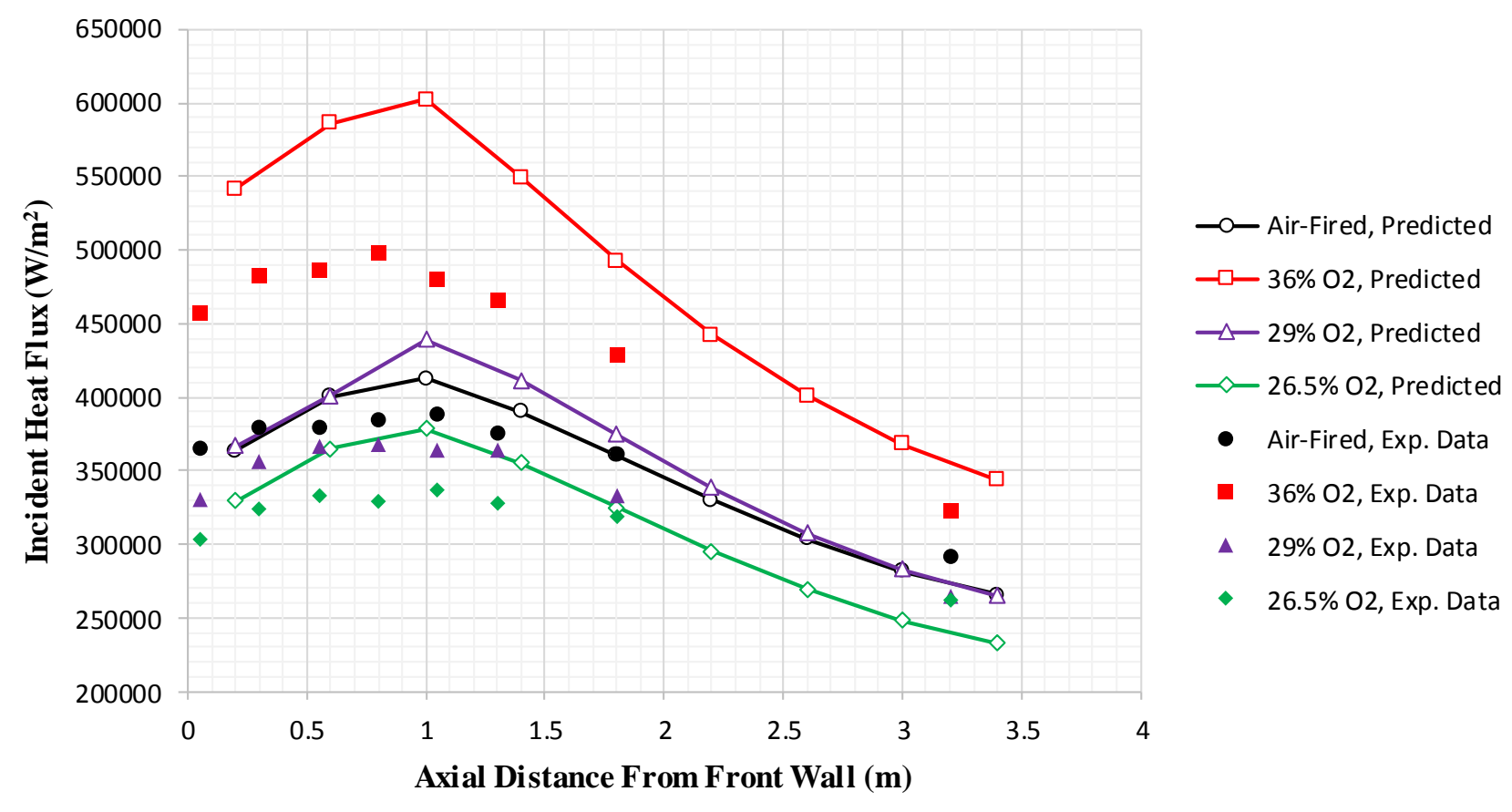

Figure 16. Predicted and measured incident heat flux profiles 


\section{Conclusions and Future Work}

A first-principles-based hybrid boiler model with 1-D resolution for mass and energy balances and reaction kinetics and 3-D resolution for radiative heat transfer was developed for the design and optimization of pulverized coal fired oxy-combustion systems. The submodels for calculating the radiative properties of the gas and particle phases and those for calculating the heterogeneous char reactions are suitable for both air-fired and oxy-fired conditions. Owing to the small size of the 3-D mesh for solving the radiative heat transfer equation and the limited number of zones for solving heterogeneous reaction kinetics and gas phase chemical equilibrium, the model can be converged in approximately one minute on a personal computer. The hybrid boiler model is also very suitable for the generation of reduced order models in algebraic form which can be used for large-scale multivariable optimization of complete oxy-combustion systems. By modeling the Hunter Unit 3 utility boiler in both air-fired and oxy-fired configurations and comparing the results with those from CFD simulations, the hybrid boiler model was found to give very comparable predictions in major boiler performance parameters such as furnace exit gas temperature, heat losses to platen superheater and enclosure walls, and unburned carbon in fly ash. By modeling a small test furnace with a heating rate of $0.5 \mathrm{MW}_{\text {th }}$, it was found that with appropriate adjustments of a "mixedness" related effectiveness factor for the char combustion and gasification reactions, the boiler model is able to correctly predict the trends of the incident radiation heat flux profile along the furnace axial length as well as the trend of the unburned carbon between the air-fired and oxy-fired configurations. It was found that the boiler model is more suitable for the simulations of large-scale utility boilers in which the local uneven distributions of gas species concentrations and other flow properties in individual zones are limited. An effectiveness factor of 0.9 for a front wall fired utility boiler was found adequate to account for the deviation from the assumption of the uniform distribution of the species concentrations. Appropriate effectiveness factors may need to be explored in the future for other firing configurations.

Compared with a CFD-based boiler model that typically requires at least a day or two to generate a 3-D computational mesh and another day or two to converge the model, the time required to get a solution by using the hybrid boiler model is reduced by at least three orders of magnitude. On the other hand, the hybrid boiler model is unable to predict the detailed information such as the local turbulent recirculating flow near the outlet of a pulverized coal burner as a CFD model does and, therefore, cannot be used for burner design. Nevertheless, the effects of boiler dimensions, fuel reactivity, and firing configurations on the overall boiler performance such as FEGT, flue gas composition, unburned carbon in fly ash, and heat release to boiler walls can be quite accurately predicted, especially for a large-scale utility boiler. The developed software could be a valuable tool for an engineer who does not have extensive CFD 
training to design the overall configuration of a boiler in both air-fired and oxy-fired conditions, replacing some company proprietary tools that are purely based on empirical correlations.

In future studies, more validation work will be carried out to find suitable model parameters to be used as model inputs such as the "mixedness" related effectiveness factor and the relationship between coal ash composition and wall emissivity. Meanwhile, the boiler model developed in this work will be used for system-wide optimization of the oxy-combustion process. Most system analysis studies of oxy-combustion rely on process simulators (e.g., Aspen Plus), and use single variable perturbations to assess the sensitivity of performance metrics (e.g., thermal efficiency) to changes in key design variables and assumed parameters. Zebian et al. $(2012,2013)$ considered simultaneous optimization of thirteen continuous design variables in a pressurized oxy-combustion system using the optimization tools in Aspen Plus. Rigorous integration and optimization of an oxy-combustion process, however, requires thousands of variables and constraints, which are beyond the capabilities of optimization methods in Aspen Plus. Thus, the authors have developed a new equation-based framework for flowsheet optimization. The "open" algebraic models allow for exact first and second derivatives to be calculated efficiently via automatic differentiation. This alleviates some convergence difficulties that historically plague flowsheeting problems. Furthermore, exact derivatives enable the use of modern large-scale optimization algorithms that have been demonstrated in other nonlinear problems with $100,000+$ variables and constraints. This novel flowsheet optimization framework was implemented in the General Algebraic Modeling Systems (McCarl, 2015) and demonstrated in several case studies focused on systems for oxy-combustion (Dowling, 2013 2015).

To integrate PDE-based models into flowsheets for optimization or simulation, a popular approach is to use a surrogate/reduced order model, which is fit to data generated using the first principles model (Edge, 2012 \& 2013). Generation of the reduced model requires sampling the multidimensional input space of the boiler model and subsequent simulation of many sampled cases. Other co-simulation studies for oxy-combustion first fit the model and the perform simulation or optimization (Edge, 2012 and 2013; Fei, 2015). However, without updates to the surrogate model, there is no way to guarantee the oxy-combustion process simulation results are valid, as the surrogate model contains some interpolation errors. Future efforts will also be taken to develop a trust region optimization algorithm, which automates surrogate model updates during optimization and guarantees convergence to the true optimum (Dowling, 2014; Eason, 2015). This new trust region method will be used to integrate the hybrid boiler model into system-wide oxy-combustion optimization. 


\section{Acknowledgment and Disclaimer}

This work was supported by the U.S. Department of Energy, Office of Fossil Energy as part of the Carbon Capture Simulation Initiative (CCSI). This technical effort was performed in support of the National Energy Technology Laboratory's ongoing research under the RES contract DE-FE0004000. This report was prepared as an account of work sponsored by an agency of the United States Government. Neither the United States Government nor any agency thereof, nor any of their employees, makes any warranty, express or implied, or assumes any legal liability or responsibility for the accuracy, completeness, or usefulness of any information, apparatus, product, or process disclosed, or represents that its use would not infringe privately owned rights. Reference herein to any specific commercial product, process, or service by trade name, trademark, manufacturer, or otherwise does not necessarily constitute or imply its endorsement, recommendation, or favoring by the United States Government or any agency thereof. The views and opinions of authors expressed herein do not necessarily state or reflect those of the United States Government or any agency thereof.

\section{Nomenclature}

\section{Symbols}

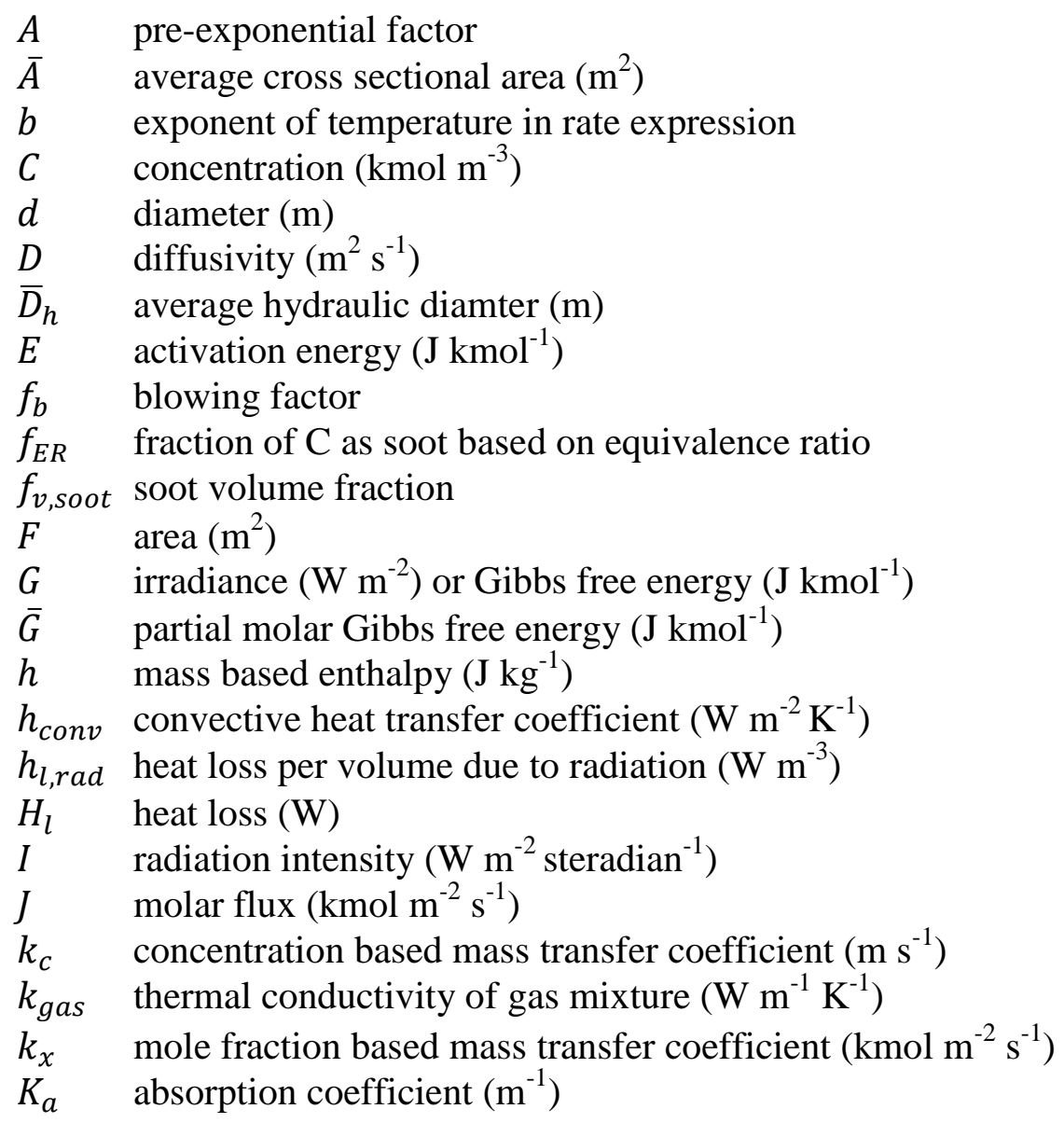




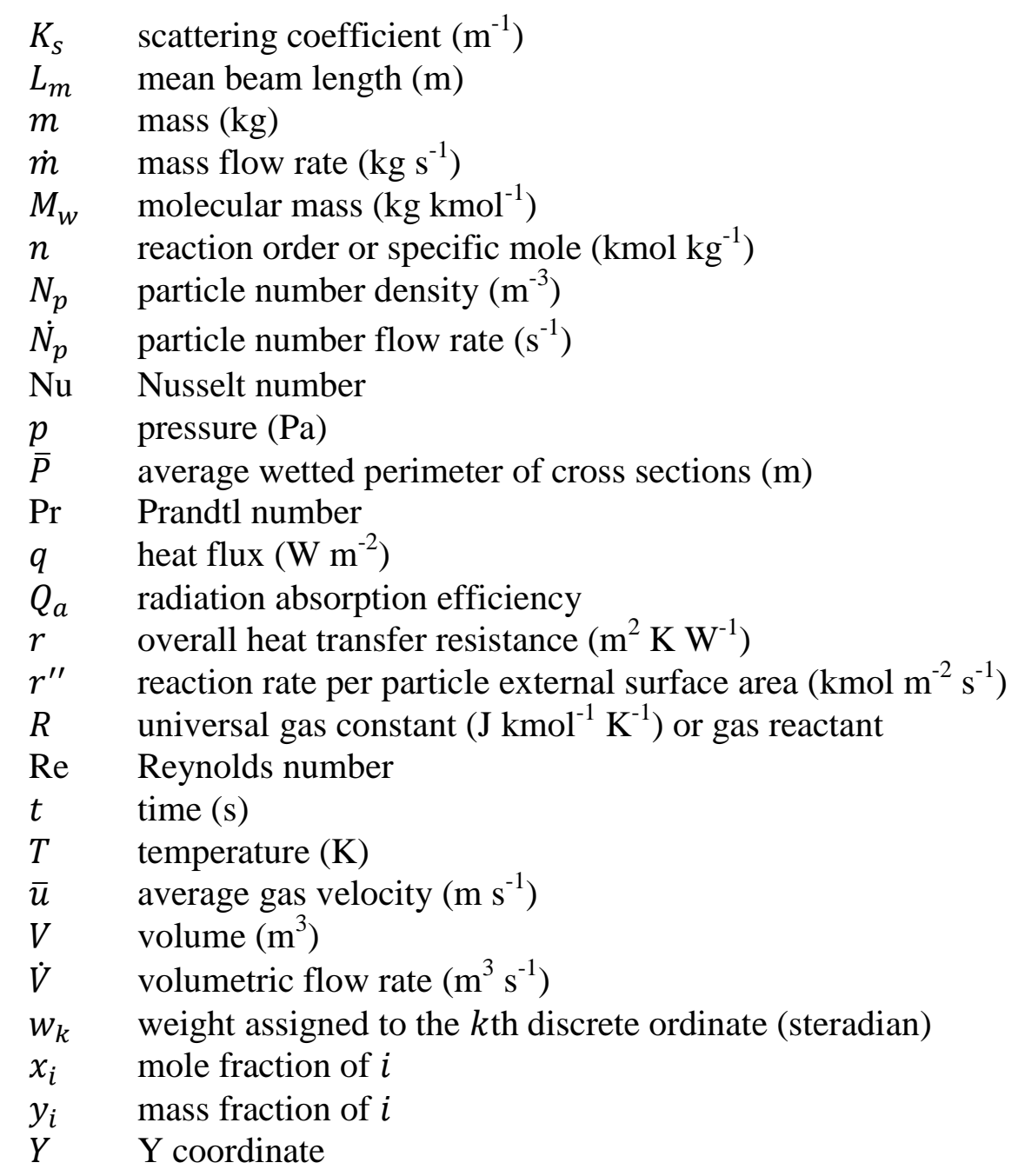

\section{Greek letters}

$\alpha \quad$ burning mode parameter

$\beta_{e, i} \quad$ number of atoms of Element $e$ in a molecule of Species $i$

$\varepsilon_{\text {tol }}$ tolerance for convergence

$\epsilon \quad$ emissivity

$\lambda$ under-relaxation factor

$\mu \quad$ viscosity $\left(\mathrm{kg} \mathrm{m}^{-1} \mathrm{~s}^{-1}\right)$

$v \quad$ stoichiometric coefficient

$\pi \quad$ ratio of a circle's circumference to its diameter

$\rho$ density

$\sigma \quad$ Stefan-Boltzmann constant $\left(\mathrm{W} \mathrm{m}^{-2} \mathrm{~K}^{-4}\right)$

$\phi \quad$ flux ratio for mass transfer or variable in non-linear equations

$\Phi$ phase function

$\psi \quad$ molar ratio of $\mathrm{CO}_{2}$ to $\mathrm{CO}$ in char oxidation reaction

$\Omega \quad$ solid angle describing the radiation direction (steradian) 


\section{Subscripts}

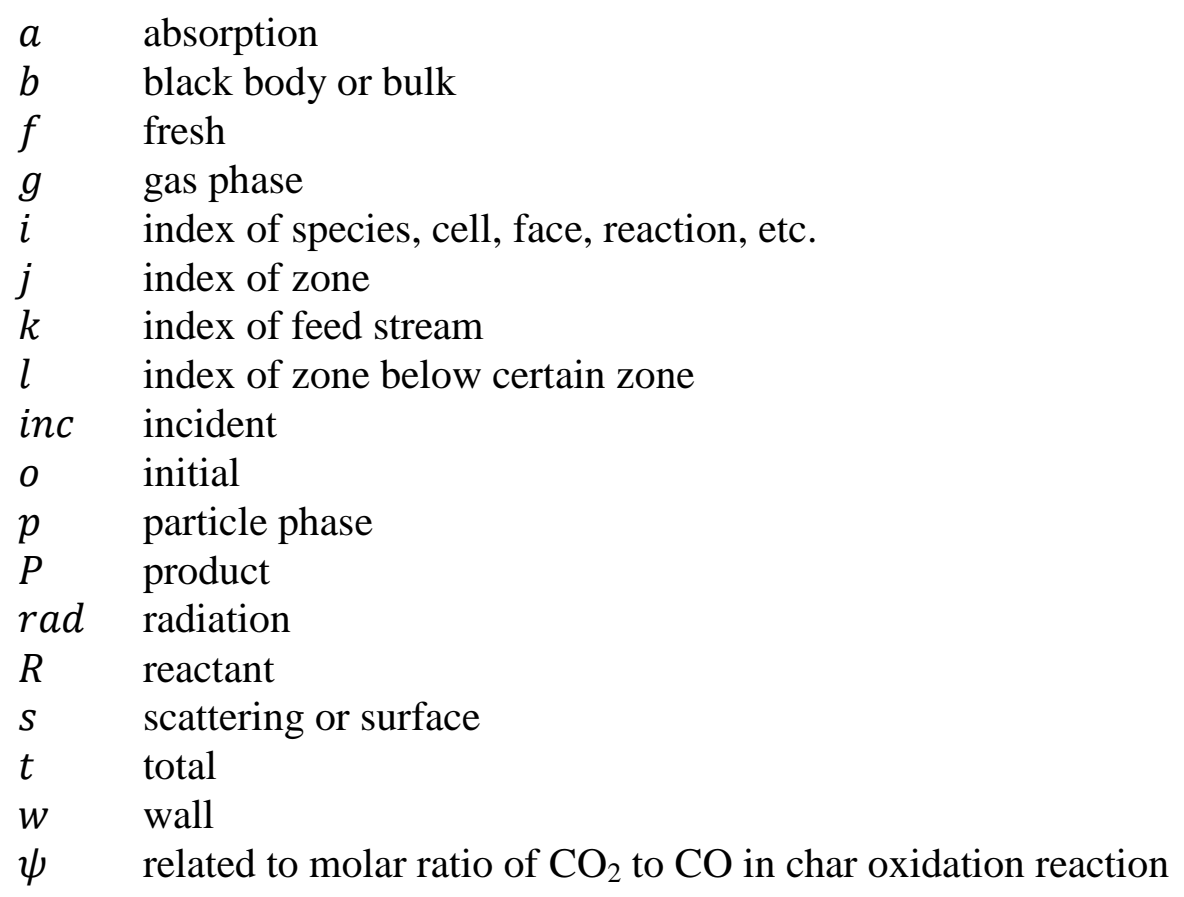

\section{References}

Adams, B. R., K. David, C. Senior, H. S. Shim, B. V. Otten, A. Fry, J. Wendt, E. Eddings, A. Paschedag, S. Zurek, C. Shaddix, and W. Cox, "Characterizaton of Oxy-combustion Impacts in Existing Coal-Fired Boilers," Final Technical Report NT0005288 (2013), available at https://www.netl.doe.gov/File\%20Library/Research/Coal/energy\%20systems/combustion/NT000 5288-Final-Report-12-19-2013.pdf

ANSYS Fluent, Fluent User's Manual (2015)

Babcock \& Wilcox, "Steam-Its Generation and Use," Chapter 4, The Babcok \& Wilcox Company, Barberton, Ohio (1992)

Beijing Boiler Works, "Normative Method for Boiler Thermal Calculations," Machinery Industry Publishing Company, Beijing (1973), [in Chinese, Translated from Russian]

Bird, R. B., W. E. Stewart and E. N. Lightfoot, "Transport Phenomena," John Wiley \& Sons, New York (1960)

Bordbar, Mohammad Hadi, Gabriel Wecel, and Timo Hyppanen, "A Line by Line Based Weighted Sum of Gray Gases Model for Inhomegeneous $\mathrm{CO}_{2}-\mathrm{H}_{2} \mathrm{O}$ Mixture in Oxy-fired Combustion," Combustion and Flame, Vol. 16, 2435-2445 (2014) 
Buhre, B. J. P., L. K. Elliott, C. D. Sheng, R. P. Gupta, and T. F. Wall, "Oxy-Fuel Combustion Technology for Coal-Fired Power Generation," Progress in Energy and Combustion Science, Vol. 31, 283-307 (2005)

Dowling, A. W., C. Balwani, Q. Gao, and L. T. Biegler, "Optimization of Sub-ambient Separation Systems With Embedded Cubic Equation of State Thermodynamic Models and Complementarity Constraints," Computers \& Chemical Engineering, in press (2015a), 10.1016/j.compchemeng.2015.04.038.

Dowling, A. W., and L. T. Biegler, "A Framework for Efficient Large Scale Equation-oriented Flowsheet Optimization," Computers \& Chemical Engineering, Vol 72, 3-20 (2015b)

Dowling, A. W., and L. T. Biegler, "Optimization-based Process Synthesis for Sustainable Power Generation," Chemical Engineering Transactions, Vol 35, 1-12 (2013)

Dowling, A. W., J. P. Eason, J. Ma, D. C. Miller, and L. T. Biegler, "Coal Oxycombustion Power Plant Optimization Using First Principles and Surrogate Boiler Models," Energy Procedia, Vol. 63, 352-361 (2014)

Eason, J. P and L.T. Biegler, "Reduced Model Trust Region Methods for Embedding Complex Simulations in Optimization Problems," Krist V. Gernaey, Jakob K. Huusom and Rafiqul Gani, Editor(s), Computer Aided Chemical Engineering, Vol 37, 773-778 (2015), ISSN 1570-7946, ISBN 9780444634290.

Edge, P.J., P.J. Heggs, M. Pourkashanian, P.L. Stephenson, and A. Williams, “A Reduced Order Full Plant Model for Oxyfuel Combustion,” Fuel, Vol. 101, 234-243 (2012)

Edge, P.J., P.J. Heggs, M. Pourkashanian, and P.L. Stephenson. "Integrated Fluid DynamicsProcess Modelling of a Coal-Fired Power Plant with Carbon Capture." Applied Thermal Engineering, Vol. 60, 242-250 (2013)

Fei, Y., S. Black, J. Szuhánszki, L. Ma, D.B. Ingham, P.J. Stanger, and M. Pourkashanian, "Evaluation of the Potential of Retrofitting a Coal Power Plant to Oxy-Firing Using CFD and Process Co-Simulation," Fuel Processing Technology, Vol. 131, 45-58 (2015)

Fiveland, W. A. "Three-dimensional radiative heat-transfer solutions by the discrete-ordinates method," Journal of Thermophysics and Heat Transfer, Vol. 2, No. 4, 309-316 (1988)

Fu, Chao, Rahul Anantharaman, and Truls Gundersen, "Optimal Integration of Compression Heat with Regenerative Steam Rankine Cycles in Oxy-Combustion Coal Based Power Plants," Energy, Vol. 84, 612-622 (2015)

$\mathrm{Fu}$, Chao and Truls Gundersen, "Heat Integration of an Oxy-Combustion Process for Coal-Fired Power Plants with $\mathrm{CO}_{2}$ Capture by Pinch Analysis," Chemical Engineering Transactions, Vol. 21, 181-186 (2010) 
Hagi, Hayato, Yann Le Moullec, Maroun Nemer, and Chakib Bouallou, "Performance Assessment of First Generation Oxy-Coal Power Plants through an Exergy-Based Process Integration Methodology," Energy, Vol. 69, 272-84 (2014)

Hottel, H. C. and A. F. Sarofim, "Radiative Transfer," New York ; London, McGraw-Hill (1967)

$\mathrm{Hu}$, Yukun and Jinyue Yan, "Numerical Simulation of Radiation Intensity of Oxy-Coal Combustion with Flue Gas Recirculation," International Journal of Greenhouse Gas Control, Vol. 17, 473-480 (2013)

Hulst, H. C. van de, "Light Scattering by Small Particles," New York, Dover Publications, Inc. (1981)

Hurt, R. H. and R. E. Mitchell, "Unified High Temperature Char Combustion Kinetics for a Suite of Coals of Various Rank," $24^{\text {th }}$ International Symposium on Combustion, The combustion Institute, Pittsburgh, PA, (1992)

Incropera, F. P. and D. P. DeWitt, "Foundamentals of Heat and Mass Transfer," $5^{\text {th }}$ Edition, John Wiley \& Sons, Hoboken, NJ (2002)

Kouznetsov, N. V., V. V. Mitor, I. E. Dubovsky, and E. S. Karasina, "Thermal Calculation of Steam Boilers: Normative Method,” Moscow, Energiya (1973), [in Russian]

Lawson, D. A. and C. D. Ziesler, "An Accurate Program for Radiation Modelling in the Design of High-temperature Furnaces," IMA Journal of Mathematics Applied in Business \& Industry 7:8 (1996)

Lowe, A., T. F. Wall, and I. M. Stewart, "A Zoned Heat Transfer Model of a Large Tangentially Fired Pulverized Coal Boiler," Symposium (International) on Combustion 15, 1261-1270 (1975)

Ma, J. and S. E. Zitney, "Computational Fluid Dynamic Modeling of Entrained-Flow Gasifiers with Improved Physical and Chemical Submodels,” Energy and Fuels, 26(12), 7195-7219 (2012)

Ma, J., A. Dowling, J. Eason, L. T. Biegler, and D. C. Miller, "Development of First Principle Boiler Model and Its Reduced Order Model for the Optimization of Oxy-combustion Power Generation System," The 39th International Technical Conference on Clean Coal \& Fuel Systems, June 1-5, Clearwater, FL (2014)

McCarl, Bruce A., Alex Meeraus, Paul van der Eijk, Michael Bussieck, Steven Dirkse, Pete Steacy, and Franz Nelissen, "McCarl GAMS User Guide, Version 24.1" GAMS Development Corporation, Washington, DC, USA (2015)

Mengüç, M. P., S. Manickavasagam, and D. A. D’Sa, "Determination of Radiative Properties of Pulverized Coal Particles From Experiments," Fuel, Vol. 73, No. 4, 613-625 (1994) 
Mie, G., "Beiträge zur Optik trüber Medien, speziell kolloidaler Metallösungen," Annalen der Physik, 25, 377-445 (1908)

Modest, Michael F., "Radiative Heat Transfer," Third Edition, Academic Press, New York (2013)

Murthy, J. Y. and S. R. Mathur, "Finite Volume Method for Radiative Heat Transfer Using Unstructured Meshes," Journal of Thermophysics and Heat Transfer, Vol. 12, No. 3 (1998)

Plaza, Piotr P., "The Development of a Slagging and Fouling Predictive Methodology for Large Scale Pulverised Boilers Fired with Coal/Biomass Blends," Ph.D. Dissertation, Cardiff University, UK (2013)

Rebola, Amandio, L. T. Azevedo Joao, "Modelling Pulverized Coal Combustion Using Air and $\mathrm{O}_{2}+$ Recirculated Flue Gas as Oxidant," Applied Thermal Engineering Vol. 83, 1-7 (2015)

Smart, John, Gang Lu, Yong Yan, and Gerry Riley, "Characterisation of an Oxy-coal Flame Through Digital Imaging," Combustion and Flame, Vol. 157, 1132-1139 (2010a)

Smart, John P., Rajeshriben Patel, and Gerry S. Riley, "Oxy-fuel Combustion of Coal and Biomass, the Effect on Radiative and Convective Heat Transfer and Burnout," Combustion and Flame, Vol. 157, 2230-2240 (2010b)

Soundararajan, Rengarajan, Rahul Anantharaman, and Truls Gundersen, "Design of Steam Cycles for Oxy-Combustion Coal Based Power Plants with Emphasis on Heat Integration," Energy Procedia, Vol. 51, 119-126 (2014)

Tranier, Jean-Pierre, Richard Dubettier, Arhur Darde, and Nicolas Perrin, "Air Separation, Flue Gas Compression and Purification Units for Oxy-Coal Combustion Systems," Energy Procedia, Vol. 4, 966-971 (2011)

William L. Grosshandler, "RADCAL: A Narrow-Band Model for Radiation Calculations in a Combustion Environment," NIST Technical Note 1402 (1993), available at http:/fire.nist.gov/bfrlpubs/PDF/f93096.pdf

Zebian, Hussam, Marco Gazzino, and Alexander Mitsos, "Multi-Variable Optimization of Pressurized Oxy-Coal Combustion,” Energy Vol. 38, 37-57 (2012)

Zebian, Hussam, Nicola Rossi, Marco Gazzino, Danila Cumbo, and Alexander Mitsos, "Optimal Design and Operation of Pressurized Oxy-Coal Combustion with a Direct Contact Separation Column,” Energy, Vol. 49, 268-78 (2013) 